\title{
Regulation of Human Mononuclear Phagocyte Migration by Cell Surface-Binding Proteins for Advanced Glycation End Products
}

Ann Marie Schmidt, Shi Du Yan, Jerold Brett, Rozalia Mora, Roman Nowygrod, * and David Stern
Departments of Physiology and *Surgery, Colurnbia University, College of Physicians and Surgeons, New York 10032

\begin{abstract}
Nonenzymatic glycation of proteins occurs at an accelerated rate in diabetes and can lead to the formation of advanced glycation end products of proteins (AGEs), which bind to mononuclear phagocytes (MPs) and induce chemotaxis. We have isolated two cell surface-associated binding proteins that mediate the interaction of AGEs with bovine endothelial cells. One of these proteins is a new member of the immunoglobulin superfamily of receptors (termed receptor for AGEs or RAGE); and the second is a lactoferrin-like polypeptide (LF-L). Using monospecific antibodies to these two AGE-binding proteins, we detected immunoreactive material on Western blots of detergent extracts from human MPs. Radioligand-binding studies demonstrated that antibody to the binding proteins blocked ${ }^{125}$ I-AGE-albumin binding and endocytosis by MPs. Chemotaxis of human MPs induced by soluble AGE-albumin was prevented in a dose-dependent manner by intact antibodies raised to the AGE-binding proteins, $F\left(\mathrm{ab}^{\prime}\right)_{2}$ fragments of these antibodies and by soluble RAGE. When MP migration in response to $\boldsymbol{N}$-formyl-Met-Leu-Phe was studied in a chemotaxis chamber with AGE-albumin adsorbed to the upper surface of the chamber membrane, movement of MPs to the lower compartment was decreased because of interaction of the glycated proteins with RAGE and LF-L on the cell surface. The capacity of AGEs to attract and retain MPs was shown by implanting polytetrafluoroethylene (PTFE) mesh impregnated with AGEalbumin into rats: within $4 \mathrm{~d}$ a florid mononuclear cell infiltrate was evident in contrast to the lack of a significant cellular response to PTFE with adsorbed native albumin. These data indicate that RAGE and LF-L have a central role in the interaction of AGEs with human mononuclear cells and that AGEs can serve as a nidus to attract MPs in vivo. (J. Clin. Invest. 1993. 91:2155-2168.) Key words: monocyte $\bullet$ glycation $\bullet$ diabetes $\bullet$ atherosclerosis
\end{abstract}

\section{Introduction}

The extended interaction of proteins with aldose sugars, such as glucose or ribose (1-3), leads to the formation of advanced glycation end products of proteins (AGEs). ${ }^{1}$ AGEs bind to

Address correspondence to Dr. Ann Marie Schmidt, Department of Physiology, Columbia University, College of Physicians and Surgeons, 630 West 168th St., New York, NY 10032.

Received for publication 28 April 1992 and in revised form 4 November 1992.

1. Abbreviations used in this paper: AGE, advanced glycation end product; EBSS, Earle's balanced salt solution; EC, endothelial cell; LF-L, lactoferrin-like; MP, mononuclear phagocyte; PTFE, polytetrafluoroethylene; RAGE, receptor for AGE; sRAGE, soluble RAGE.

J. Clin. Invest.

(c) The American Society for Clinicai Investigation, Inc.

$0021-9738 / 93 / 05 / 2155 / 14 \$ 2.00$

Volume 92, May 1993, 2155-2168 endothelial cells (ECs) and mononuclear phagocytes (MPs) and alter cellular functions. Exposure of cultured ECs to AGEs perturbs barrier and coagulant function of the cell monolayer and stimulates cell growth $(4,5)$. MP-AGE interaction leads to cell activation, as evidenced by the induction of MP migration, as well as release of cytokines and platelet-derived growth factor $(6,7)$.

The accumulation of AGEs in the vessel wall, especially in diabetes, where their capacity to perturb endothelial and MP functions may contribute to the development of vascular lesions, has prompted several investigators to study interactions of AGEs with macrophages and endothelial cells (8-12). Radoff et al. (9) and Yang et al. (11) identified two cell surface proteins on rodent macrophages that may be involved in the cellular interaction with AGEs: a $90-\mathrm{kD}$ polypeptide that interacts with furanyl-furoyl-imidazole (a synthetic compound possibly related to AGEs) ( 9 ) and a $60-\mathrm{kD}$ polypeptide that reacts directly with AGE-albumin (11). We have isolated and characterized two polypeptides from extracts of bovine lung on the basis of their ability to bind AGEs: a protein that is a new member of the immunoglobulin superfamily of receptors (termed receptor for AGEs or RAGE) and a lactoferrin-like (LF-L) AGE-binding protein $(8,10)$. RAGE and the LF-L polypeptide are both present on the surface of bovine ECs, and specific antibodies to each of these polypeptides block the binding of ${ }^{125} \mathrm{I}$-AGE-albumin to ECs (10).

In this study, we have identified RAGE and the LF-L AGE-binding protein in human MPs and have demonstrated that these polypeptides mediate the binding and endocytosis of ${ }^{125} \mathrm{I}$-AGE-albumin by MPs. Whereas engagement of these polypeptides by soluble AGE-albumin induces MP chemotaxis, interaction of these MP cell surface receptors with immobilized AGEs slows their migration. These results demonstrate that RAGE and the LF-L AGE binding protein have a central role in mediating the effects of AGEs on MPs and suggest that soluble AGEs could attract MPs into vessel walls and tissues, where deposits of immobilized AGEs could lead to their retention. This work outlines a possible mechanism, in addition to the formation of oxidized lipoproteins (13), through which modified proteins can draw monocytes into the vessel wall.

\section{Methods}

Preparation of human MPs. Human peripheral blood monocytes were isolated from the blood of normal healthy volunteers (13). Blood was centrifuged on Histopaque 1077 (Sigma Chemical Co., St. Louis, $\mathrm{MO}$ ), the mononuclear cell fraction was obtained, washed twice in Earle's balanced salt solution (EBSS), resuspended in RPMI 1640 containing human serum ( $10 \%$; Gemini, Calabasas, CA), plated on 100 $\mathrm{mm}$ tissue culture dishes, and incubated at $37^{\circ} \mathrm{C}$ for $1-2 \mathrm{~h}$. Nonadherent cells were removed by washing the plate twice with EBSS and adherent cells were harvested by incubation with calcium-magnesiumfree EBSS containing EDTA $(2 \mathrm{mM})$ for $15 \mathrm{~min}$ at $37^{\circ} \mathrm{C}$ followed by extensive washing in EBSS and resuspension in RPMI 1640 containing human serum (10\%) at a concentration of $10^{6}$ cells $/ \mathrm{ml}(10)$. 
Preparation of glycated proteins in vitro, $A G E$-binding proteins, and antibodies. AGE albumin was prepared by incubating bovine serum albumin (fraction V; Sigma Chemical Co.) with either glucose-6-phosphate ( $250 \mathrm{mM}$; Sigma Chemical Co.), glucose ( $0.5 \mathrm{M}$; Sigma Chemical Co.), or ribose ( $250 \mathrm{mM}$; Sigma Chemical Co.) at $37^{\circ} \mathrm{C}$ for $6-8 \mathrm{wk}$. Glycated proteins were characterized by their identical binding properties to ECs and purified AGE-binding proteins, as reported previously $(5,10)$, and by their fluorescence (1). Isoelectric focusing demonstrated that the pIs were very similar for AGE-albumin prepared in the presence of either glucose, ribose, or glucose-6-phosphate $(\mathrm{pI} \approx 4.55$ ) (the $\mathrm{pI}$ of native albumin was $\approx 4.7-4.9$ ), and SDS-PAGE showed a single major band. Collagen I (Collaborative Research, Bedford, MA) was glycated using the same procedure. Controls consisted of the same initial preparations of albumin and collagen I incubated at $37^{\circ} \mathrm{C}$ in an identical fashion, except that aldoses were omitted from the reaction mixture. Radiolabeling of albumin/AGE-albumin was accomplished by the lactoperoxidase method using Enzymobeads (Bio-Rad Laboratories, Richmond, $\mathrm{CA}$ ), and the final specific radioactivity of the tracers was $\approx 1.5 \times 10^{3} \mathrm{cpm} / \mathrm{ng}(10)$.

AGE-binding proteins were purified to homogeneity from a detergent extract of bovine lung acetone powder (10). RAGE migrated as a single band on reduced and nonreduced SDS-PAGE with a relative molecular mass of $\approx 35 \mathrm{kD}$. This form of RAGE has been termed soluble RAGE (sRAGE), as it probably represents the amino terminal two thirds of the molecule (8). Before use in chemotaxis assays, SRAGE was dialyzed versus PBS containing octyl- $\beta$-glucoside $(0.01 \%)$. Purified LF-L AGE-binding protein also migrated as a single band on SDS-PAGE with a relative molecular mass of $\approx 80 \mathrm{kD}(10)$. Antibodies prepared to each of the AGE-binding proteins in rabbits and guinea pigs have been shown to be monospecific, on the basis of Western blotting studies in which antibody staining of a single protein in EC (10) or partially purified lung (data not shown) extracts could be blocked by addition of the respective, purified, soluble AGE-binding protein. Antisera were chromatographed on protein A-agarose to purify the IgG fraction. In addition, for the LF-L AGE-binding protein, antibody was affinity purified on a lactoferrin-affi-gel 10 column. Lactoferrin ( $100 \mathrm{mg}$; Sigma Chemical Co.) was bound to affi-gel $10(25 \mathrm{ml}$; Bio-Rad Laboratories, Sacramento, CA) according to the manufacturer's instructions (coupling efficiency $\approx 90 \%$ ). Anti-LF-L serum ( 5 $\mathrm{ml})$ was applied to the lactoferrin-affi-gel $10(25 \mathrm{ml})$, and after extensive washing the adsorbed immunoglobulins were eluted with glycine buffer $(0.2 \mathrm{M} ; \mathrm{pH} 2.5)$. The eluate was rapidly neutralized with Tris to pH 7.4 and then dialyzed versus Tris-buffered saline (Tris, $20 \mathrm{mM}$, pH $7.4 ; \mathrm{NaCl} 0.1 \mathrm{M}$ ). As a control for experiments employing anti-AGEbinding protein antibodies, studies were performed with polyclonal rabbit anti-human CD4 IgG (this antibody was generously provided by Dr. Seth Lederman, Department of Medicine.) This antiserum was prepared by immunizing rabbits by standard methods with purified recombinant human CD4 (14), generously provided by Biogen (Cambridge, MA), and shown to be present on the surface of human MPs (15). The IgG fraction was purified as above and found to be monospecific for CD4, on the basis of Western blotting of Jurkat $T$ cell lysates. In addition, this immune IgG stains the surface of monocytoid cells by FACS analysis and immunoprecipitates CD4 from Jurkat T cell lysates.

$F\left(a b^{\prime}\right)_{2}$ fragments of the immune IgG raised to RAGE and LF-L AGE-binding protein were prepared by pepsin digestion of IgG fractions for $6 \mathrm{~h}$ at $37^{\circ} \mathrm{C}(5 \mu \mathrm{g}$ pepsin $/ \mathrm{mg}$ of $\mathrm{IgG}$ in $100 \mathrm{mM}$ sodium citrate buffer). The reaction was stopped by the addition of $1 / 10 \mathrm{vol}$ of Tris ( 3 $\mathrm{M} ; \mathrm{pH} \mathrm{8.8),} \mathrm{followed} \mathrm{by} \mathrm{centrifugation} \mathrm{at} 10,000 \mathrm{~g}$ for $30 \mathrm{~min}$, and the digest was dialyzed against PBS. $\mathrm{F}\left(\mathrm{ab}^{\prime}\right)_{2}$ fragments were separated from other components of the reaction mixture using a protein A-Sepharose CL-4B (Pharmacia Inc., Piscataway, NJ) column. The pass-through was collected, and the purity of the $F\left(a b^{\prime}\right)_{2}$-containing fractions was determined by SDS-PAGE. To test the effect of intact antibodies or their $\mathrm{F}\left(\mathrm{ab}^{\prime}\right)_{2}$ fragments in chemotaxis assays, suspensions of monocytes $\left(10^{6} / \mathrm{ml}\right)$ were preincubated for $1 \mathrm{~h}$ in RPMI 1640 containing fetal bovine serum $(1 \%)$ and the indicated immune $\operatorname{IgG}, F\left(a b^{\prime}\right)_{2}$ or nonimmune guinea pig $\operatorname{IgG}$ at $4^{\circ} \mathrm{C}$. Cells were then washed twice in EBSS and resuspended in RPMI 1640 containing fetal bovine serum $(1 \%)$ at a concentration of $2 \times 10^{5}$ cells $/ \mathrm{ml}$ for chemotaxis assays.

Antibodies to AGE-moieties on proteins were prepared by immunizing guinea pigs with AGE-albumin or AGE-keyhole limpet hemocyanin and affinity purifying the antibody population that selectively recognized AGEs (not the native protein backbone) through sequential chromatography on columns with immobilized native protein and then AGE-moiety. (Yan, S. D., A. M. Schmidt, J. Brett, and D. Stern, manuscript is in preparation concerning the characterization of the anti-AGE antibodies) This population of antibodies was used to develop an ELISA assay for AGEs. In brief, ELISA wells were coated with a range of concentrations of AGE albumin (0.025-250 $\mu \mathrm{g}$ per well) overnight at $4^{\circ} \mathrm{C}$ in carbonate buffer ( $\left.\mathrm{pH} 9\right)$. Wells were washed three times $(0.1 \mathrm{ml}$ per wash) with Dulbecco's PBS containing Tween 20 $(0.05 \%)$, excess sites in the well were blocked by incubation with goat serum ( $1 \%$ ) in PBS for $2 \mathrm{~h}$ at $37^{\circ} \mathrm{C}$, and then wells were washed again as above. A range of dilutions of patient plasma, either that derived from healthy volunteers $(<41 \mathrm{yr})$ or individuals with diabetes, was added to wells along with a standard concentration of antibody (1:1,600 dilution) for $2 \mathrm{~h}$ at $37^{\circ} \mathrm{C}$. Wells were then washed, secondary antibody was added, peroxidase-conjugated goat anti-guinea pig IgG (Sigma Chemical Co.), for $1 \mathrm{~h}$ at $37^{\circ} \mathrm{C}$ and $O$-phenylenediamine (Sigma Chemical Co.) was used to visualize bound antibody. The reaction was stopped with sulfuric acid and $\mathrm{OD}_{495}$ was determined. This ELISA was used to select diabetic plasma from which AGEs were isolated as described below. By immunofluorescence, anti-AGE antibodies did not specifcally stain human MPs.

The anti-AGE antibody was also coupled to affi-gel 10 according to the manufacturer's instructions, and then the resin was incubated with plasma from diabetics (plasma of two patients with diabetes, which contained AGEs by ELISA, was pooled) or normal patients (plasma of two individuals that were negative for AGEs) for $2 \mathrm{~h}$ at $37^{\circ} \mathrm{C}(20 \mathrm{ml}$ of plasma $/ 10 \mathrm{ml}$ of resin). The resin was washed extensively with Tris (20 mM; pH 7.4)-buffered saline (0.1 M). Material bound to the resin was eluted with a high salt $(\mathrm{NaCl}, 1 \mathrm{M})$ wash, and the eluate was dialyzed versus Tris-buffered saline. The latter material was concentrated using Centricon tubes (MWCO 10,000; Amicon, Beverly, MA), and protein concentration was determined by standard protein assay (Bio-Rad). Negligible protein was detectable in the eluate from the column to which normal plasma had been applied, so that similar volumes of column eluate were processed in a manner identical to that for samples from diabetic plasma. This material was used in chemotaxis assays with MPs as described below.

Western blotting. For samples blotted with anti-RAGE IgG, human MPs $\left(10^{8}\right.$ cells $)$ prepared as described above were solubilized in Tris (20 mM; pH 7.4), $\mathrm{NaCl}(0.1 \mathrm{M})$, octyl- $\beta$-glucoside (1\%), and PMSF ( $1 \mathrm{mM}$ ), and chromatographed on hydroxylapatite ( $10 \mathrm{ml}$; IBF Biotechnics, Columbia, MD). The resin was washed extensively with Trisbuffered saline ( Tris, $20 \mathrm{mM}$, pH 7.4; $\mathrm{NaCl}, 0.1 \mathrm{M}$ ) containing octyl- $\beta$ glucoside $(0.1 \%)$ and eluted in the same buffer with the final $\mathrm{NaCl}$ concentration adjusted to $1 \mathrm{M}$. For samples to be analyzed with antiLF-L IgG, the cell pellet was solubilized directly in SDS-PAGE sample buffer without reducing agent (16). In both cases the cell extracts were then applied to SDS-PAGE (10\%) and subjected to Western blotting by the Blotto procedure (17) except that membranes containing LF-L AGE-binding protein were blocked with albumin solution ( $5 \%$ ) rather than nonfat dry milk. After reaction with primary antibody (antiRAGE IgG or anti-LF-L IgG), sites of IgG binding were visualized by chemiluminescence using peroxidase-conjugated secondary antibody (Amersham Corp., Arlington Heights, IL) or using the same antibody developed with 3,3'-diaminobenzidine tetrahydrochloride (Sigma Chemical Co.).

To prove that the two AGE-binding proteins were distinct and not common subunits of a single receptor, detergent extracts from MPs $\left(10^{8}\right.$ cells, prepared as described above) were chromatographed on im- 
munoaffinity columns with immobilized anti-RAGE IgG or anti-LF-L IgG. The latter columns were prepared by coupling $15 \mathrm{mg}$ of either anti-RAGE IgG or anti-LF-L IgG to affi-gel 10 . In each case, MP detergent extract $(5 \mathrm{ml})$ was incubated with anti-RAGE IgG-affi-gel or antiLF-L IgG-affi-gel $\left(5 \mathrm{ml}\right.$ in each case) overnight at $4^{\circ} \mathrm{C}$. The passthrough was collected, the resin was then washed extensively in Trisbuffered saline containing octyl- $\beta$-glucoside $(0.1 \%)$, and the column was eluted with either $\mathrm{NaCl}$ ( $1 \mathrm{M}$ ) (anti-RAGE IgG-aff-gel) or glycine $(0.2 \mathrm{M}, \mathrm{pH} 2.5)$ (anti-LF-L IgG-affi-gel) (although similar results were obtained when the anti-RAGE IgG-affi-gel was eluted with acidic glycine buffer, since elution of RAGE was complete in high salt buffer, the latter approach was used to enhance stability of the immobilized antibodies, which appeared to deteriorate more rapidly with multiple exposures to acidic conditions). The pass-through and eluted fractions from each column were dialyzed overnight versus Tris-buffered saline containing octyl- $\beta$-glucoside $(0.1 \%)$. Fractions were then subjected to SDS-PAGE ( $10 \%)$ followed by Western blotting with anti-RAGE IgG and anti-LF-L IgG as above.

Immunofluorescence. Mononuclear cells, isolated as described above, were allowed to adhere to $12-\mathrm{mm}$ coverslips for $2 \mathrm{~h}$ at $37^{\circ} \mathrm{C}$. Adherent cells were washed with balanced salt solution and fixed in paraformaldehyde $(2 \%)$ in PBS ( $\mathrm{pH} \mathrm{7.2)}$ ). Fixed nonpermeabilized mononuclear cells were incubated with guinea pig anti-RAGE IgG or anti-LF-L IgG $(\approx 50 \mu \mathrm{g} / \mathrm{ml})$ for $60 \mathrm{~min}$ at $37^{\circ} \mathrm{C}$ and, after washing, surface distribution of primary antibody was revealed with FITC-conjugated rabbit anti-guinea pig IgG (Sigma Chemical Co.). Where indicated, nonimmune guinea pig IgG replaced immune IgG at the same concentration as primary antibody.

Assays of radioligand binding and cellular processing of ${ }^{125} I-A G E-$ albumin by MPs. Human MPs were plated in 96-well plates $\left(5 \times 10^{4}\right.$ cells per well) in RPMI 1640 containing human serum (10\%) and binding assays were performed within $5 \mathrm{~d}$ as follows: cells washed three times with warm $\left(37^{\circ} \mathrm{C}\right) \mathrm{HBSS}$ were incubated with binding buffer $(0.05 \mathrm{ml}$; MEM containing fetal calf serum, $1 \%)$ and the indicated concentration of ${ }^{125} \mathrm{I}-\mathrm{AGE}$-albumin (either radiolabeled glucose-6phosphate albumin, glucose albumin, or ribose albumin) alone or in the presence of an excess of unlabeled AGE-albumin (20-fold molar excess) or the unlabeled respective aldose sugar $(25 \mathrm{mM})$ for $3 \mathrm{~h}$ at $4^{\circ} \mathrm{C}$. Binding of ${ }^{125} \mathrm{I}$-AGE-albumin was terminated by washing cultures five times with cold HBSS, and cell-bound material was eluted during a 5-min incubation at $37^{\circ} \mathrm{C}$ with buffer-containing heparin $(1 \mathrm{mg} / \mathrm{ml})$ $(5,10)$. For assays employing antibodies, IgGs at the indicated dilutions were preincubated with MPs in binding buffer at $4^{\circ} \mathrm{C}$ for $2 \mathrm{~h}$, cells were washed in HBSS, and then experiments were performed as above. Results of binding studies represent the mean \pm SE of at least quadruplicate determinations. Equilibrium binding data were analyzed by the equation of Klotz and Hunston ( 18) using nonlinear least-squares analysis (Enzfitter), as described previously (10).

Cell-associated radioligand was divided into cell surface-bound and internalized pools on the basis of the following elution techniques. Binding studies were performed by incubating ${ }^{125} \mathrm{I}-\mathrm{AGE}$ albumin with $\operatorname{MPs}\left(5 \times 10^{4}\right.$ cells per 96 well $)$ for $3 \mathrm{~h}$ at $4^{\circ} \mathrm{C}$, washing, and then eluting cell-bound material by $5 \mathrm{~min}$ of exposure of cells to Tris-buffered saline containing either heparin $(1 \mathrm{mg} / \mathrm{ml})$, sodium acetate $(20 \mathrm{mM} ; \mathrm{pH} 2)$, dextran sulfate $(1 \mathrm{mg} / \mathrm{ml})$, trypsin $(0.01 \mathrm{U} / \mathrm{ml})$ or Nonidet $\mathrm{P}-40$ (1\%). The amount of cell-associated radioligand eluted by each of these procedures was comparable and was considered to be bound to the cell surface. None of these agents altered cell viability or resulted in detachment of MPs from the plastic surface under these conditions (except for the detergent, which dissolved the cell monolayer). Similar experiments were performed after incubation of ${ }^{125} \mathrm{I}$-AGE albumin with MPs at $37^{\circ} \mathrm{C}$. After elution of cell surface-bound ${ }^{125} \mathrm{I}-\mathrm{AGE}$-albumin with heparin or trypsin, as above, the additional pool of radioactivity eluted by subsequent incubation with Nonidet P-40 (1\%) was considered to be internalized/endocytosed. This was verified morphologically by studies employing AGE-albumin linked to colloidal gold (see below).
For internalization experiments, MPs $\left(10^{6}\right.$ cells per well $)$ plated in 24-well tissue culture dishes were washed twice with HBSS and incubated with binding buffer $(0.4 \mathrm{ml})$ containing ${ }^{125} \mathrm{I}$-AGE-albumin ( 100 $\mathrm{nM}$; glucose-6-phosphate-albumin) alone or in the presence of a 20 fold molar excess of unlabeled AGE-albumin for the indicated times at $37^{\circ} \mathrm{C}$. When antibodies to the AGE-binding proteins were used before warming cultures, MPs were incubated with IgGs for $1 \mathrm{~h}$ at $4^{\circ} \mathrm{C}$. After the internalization assay at $37^{\circ} \mathrm{C}$, MPs were washed five times with cold HBSS, and heparin-containing elution buffer $(0.5 \mathrm{ml})$ was added for $5 \mathrm{~min}$ at $37^{\circ} \mathrm{C}$ to elute surface-bound tracer. Subsequently, Trisbuffered saline (Tris, $20 \mathrm{mM}, \mathrm{pH} 7.4 ; \mathrm{NaCl}, 0.1 \mathrm{M}$ ) containing Nonidet $\mathrm{P}-40(1 \%)$ was added for $5 \mathrm{~min}$ at $37^{\circ} \mathrm{C}$ to release the internalized pool of radioligand.

Surface binding and cellular uptake of AGE-albumin gold conjugates. AGE-albumin (glucose-6-phosphate albumin) colloidal gold conjugates were prepared and used by the general method described previously $(19,20)$. In brief, suspensions of colloidal gold were prepared (21) with an average diameter of $25 \mathrm{~nm}$ (22) and conjugated to albumin at pH 6.0. Complete surface labeling was achieved as determined by the serial electrolyte test (23) and labeled colloids were evaluated for stability as previously described (24). Experiments with goldlabeled AGE-albumin were carried out according to the same general protocols outlined above for radiolabeled AGE-albumin. After binding of gold particles to the surface, unbound particles were removed by washing (in certain cases, bound particles were removed by heparin elution), and samples were prepared for electron microscopy: samples were fixed in $2.5 \%$ glutaraldehyde in $0.1 \mathrm{M}$ cacodylate buffer for 30 min, postfixed in $2 \%$ osmium tetroxide, dehydrated in ethanol, and embedded in EPON. Sections were viewed in an electron microscope (model 300; Phillips Sci., Mahwah, NJ).

Chemotaxis assays. Chemotaxis assays were performed in 48-well microchemotaxis chambers (Neuro Probe, Bethesda, MD) containing a polycarbonate membrane ( $5 \mu \mathrm{m}$; Nucleopore, Pleasanton, CA ). MPs were suspended in RPMI 1640 containing fetal bovine serum (1\%), and $10^{4}$ cells were added per well to the upper chamber. The lower chamber contained the chemotactic stimulus and other agents, as indicated. Assays were performed in triplicate-quadruplicate over a 4-h incubation period at $37^{\circ} \mathrm{C}$, after which nonmigrating cells were removed, membranes were fixed in methanol, and migrating cells were visualized with Wright's stain. Cells in nine high-power fields were counted, and the mean and SEM were determined. The results are representative of at least two or more replicate experiments.

Assays with AGEs immobilized on the membrane in the chemotaxis chamber. These experiments were performed according to the general method of Aznavoorian et al. (25). In brief, before the chemotactic assay, Nucleopore membranes $(5 \mu \mathrm{m})$ were floated on a solution of AGE-albumin or control albumin $(500 \mathrm{nM})$ in calcium-magnesium-free Dulbecco's PBS at $37^{\circ} \mathrm{C}$ overnight and then air dried. In certain experiments an 100-fold molar excess of $s R A G E$ was incubated for $1 \mathrm{~h}$ at $37^{\circ} \mathrm{C}$ with the AGE-albumin or native albumin-coated membranes. The membranes were then washed and MP migration assays were performed with the coated surface of the membrane facing the upper or lower chamber, as indicated.

Phagokinetic track assays. Cell motility on surfaces coated with AGE-albumin or native albumin was assayed by the phagokinetic track technique as described by Albrecht-Buehler (26). Coverslips were coated with protein by dipping them into solution of AGE-albumin or native albumin $(25 \mathrm{mg} / \mathrm{ml}$ in each case; Sigma Chemical Co.), draining the coverslip, exposing it to $100 \%$ ethanol, and finally drying it in a stream of hot air. Colloidal gold solution was prepared by mixing 1.8 $\mathrm{ml}$ of gold chloride ( $0.5 \%$; Fischer Scientific, New York), $6 \mathrm{ml}$ of sodium carbonate $(36.5 \mathrm{mM})$, and $11 \mathrm{ml}$ of double-distilled water, boiling, and then adding $1.8 \mathrm{ml}$ of formaldehyde $(0.1 \%)$. Gold particles formed immediately, as indicated by appearance of a reddish-brown color. Hot gold solution $\left(80-90^{\circ} \mathrm{C}\right)$ was added to albumin-coated coverslips in 24-well tissue culture plates, incubated for $45 \mathrm{~min}$, and then coverslips were washed twice in cell culture medium. For phagokinetic 
track assays, cells were plated on gold-coated coverslips and incubated $6 \mathrm{~h}$ at $37^{\circ} \mathrm{C}$ in a humified atmosphere. At the end of the incubation period, coverslips were fixed in paraformaldehyde $(3.5 \%)$ in PBS, mounted in PBS-glycerol, and viewed by dark-field microscopy. The same procedure was used to study MP migration on substrates composed of AGE-collagen I and native collagen I.

Implantation of AGE-derivatized polytetrafluoroethylene (PTFE) tubes into rats. Tubes of PTFE mesh (diameter, $1 \mathrm{~cm}$; length $2 \mathrm{~cm}$; 90- $\mu \mathrm{m}$ pore size; Gortex; generously provided by W. L. Gore, Inc. Wakefield, MA) were incubated in solutions containing either AGE-albumin or native albumin (the native albumin had been incubated 6-8 wk at $37^{\circ} \mathrm{C}$ in the absence of glucose), each at a concentration of 500 $\mu \mathrm{g} / \mathrm{ml}$, for $16 \mathrm{~h}$ at $4^{\circ} \mathrm{C}$. Adsorption of each of these proteins was tested by inclusion of trace amounts of ${ }^{125} \mathrm{I}$-AGE-albumin or ${ }^{125} \mathrm{I}$-albumin in the protein-coating solutions and was found to be comparable. PTFE tubes were washed extensively in sterile saline and immediately implanted into the subcutaneous tissue of rats. At the indicated times, the dermal layer containing the PTFE tubes was excised, fixed in buffered Formalin (10\%), embedded in paraffin, and sectioned. The sections were stained with hematoxylin and eosin.

\section{Results}

Detection of RAGE and the LF-L AGE-binding protein in human MPs. In a previous study to characterize cell surface AGEbinding proteins, two polypeptides derived from bovine lung that mediate the interaction of AGEs with endothelium were identified: RAGE and LF-L AGE-binding protein (10). On the basis of biochemical and molecular cloning studies, RAGE is a new member of the immunoglobulin superfamily of receptors that specifically binds AGEs and is present on the surface of bovine ECs $(8,10)$. Monospecific polyclonal antibodies raised to bovine RAGE in guinea pigs were used to detect immunoreactive material on Western blots of protein extracted from membrane-rich fractions of human MPs (Fig. $1 A$ ). Two bands were visible in the MP-derived fractions, corresponding to relative molecular masses of $\approx 32$ and $\approx 45 \mathrm{kD}$ (lane 1 ) compared with purified bovine lung RAGE in which a single band with relative molecular mass $\approx 35 \mathrm{kD}$ (lane 2 ) was ob-
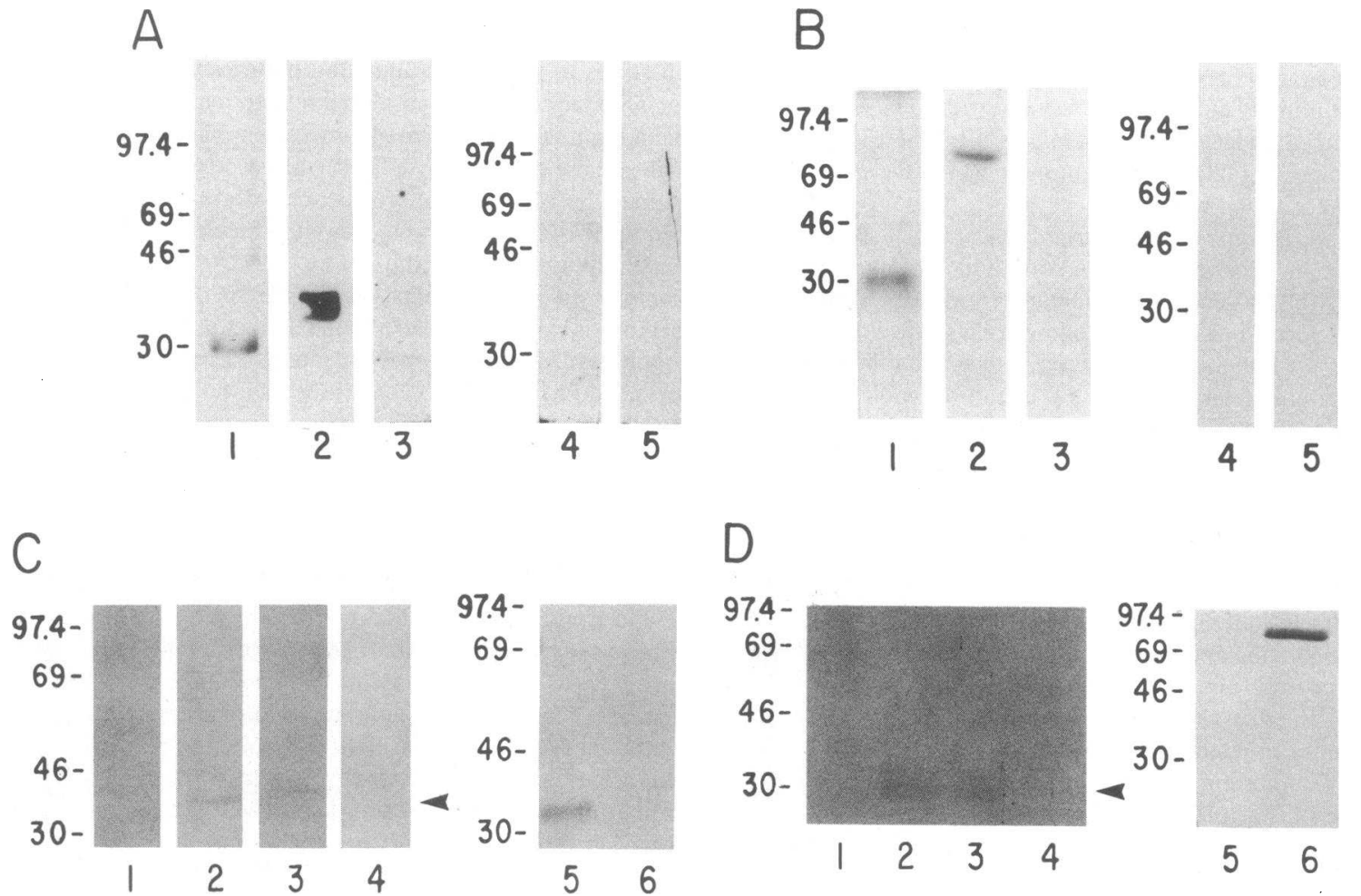

Figure 1. Immunoblotting of detergent extracts of MPs with anti-RAGE IgG and anti-LF-L IgG. $(A)$ Anti-RAGE IgG. Detergent extracts of human MPs (lane 1) and purified RAGE ( $7.5 \mu \mathrm{g})$ and LF-L $(7.5 \mu \mathrm{g})$ from bovine lung, respectively (lanes 2 and 3) were subjected to SDS-PAGE ( $10 \%$; nonreduced $)$, electroblotting, and then blots were reacted with anti-RAGE $\operatorname{IgG}(55 \mu \mathrm{g} / \mathrm{ml})$. Sites of primary antibody binding were visualized with an horseradish peroxidase-conjugated secondary antibody. The same experiment was performed in lanes 4 and 5 (samples were extract of MP and purified RAGE, respectively), but SRAGE $(500 \mu \mathrm{g} / \mathrm{ml})$ was added during incubation of the primary antibody with the blot. (B) Anti-LF-L IgG. MPs solubilized in nonreduced SDS-PAGE sample buffer (lane 1) and purified LF-L (7.5 $\mu \mathrm{g}$ ) and RAGE (7.5 $\mu \mathrm{g}$ ) from bovine lung, respectively (lanes 2 and 3 ), were subjected to SDS-PAGE (10\%; nonreduced), electroblotting, and then blots were reacted with anti-LF-L IgG $(5 \mu \mathrm{g} / \mathrm{ml})$. Sites of primary antibody binding were visualized as above. The same experiment was performed in lanes 4 and 5 (samples were extract of MP and purified RAGE, respectively), but soluble LF-L $(75 \mu \mathrm{g} / \mathrm{ml}$ ) was added during incubation of the primary antibody with the blot. $(C)$ Detergent extracts of MPs were adsorbed to either anti-RAGE IgG-affi-gel or anti-LF-L IgG-affi-gel, and the pass-through or eluates were subjected to Western blotting with anti-RAGE IgG. The pass-through and eluate from the anti-RAGE IgG-affi-gel are shown in lanes 1 and 3, respectively. The pass-through and eluate from the anti-LF-L IgG-affi-gel are shown in lanes 2 and 4, respectively. Lanes 5 and 6 contain RAGE or LF-L, respectively, purified from bovine lung. $(D)$ Detergent extracts of MPs treated as in $(C)$ above were subjected to Western blotting with anti-LF-L IgG. The pass-through and eluate from the anti-LF-L-affi-gel are shown in lanes 1 and 3, respectively, and the passthrough and eluate from the anti-RAGE IgG-affi-gel are shown in lanes 2 and 4, respectively. Lanes 5 and 6 contain RAGE or LF-L, respectively, purified from bovine lung. The migration of standard proteins run simultaneously is shown: $97.4 \mathrm{kD}$ (phosphorylase B), $69 \mathrm{kD}$ (bovine serum albumin ), $46 \mathrm{kD}$ (ovalbumin), and $30 \mathrm{kD}$ (carbonic anhydrase). These experiments were repeated at least three times. 
served. In contrast, anti-RAGE IgG did not stain purified LF-L (lane 3). Addition of excess soluble purified RAGE during incubation of blots with anti-RAGE IgG prevented the appearance of the bands from MPs and lung (lanes 4 and 5), indicating that in each instance these bands resulted from reaction of the antibody with determinants present in RAGE. However, the presence of excess soluble LF-L AGE-binding protein did not diminish the intensity of bands immunoreactive with the anti-RAGE antibody (data not shown). The presence of two different size immunoreactive RAGE polypeptides in extracts from MPs was a variable finding and probably reflected posttranslational processing/cleavage, as several lower molecular mass forms of RAGE (from $55 \mathrm{kD}$ and lower) were previously observed in 293 cells transfected with full-length RAGE cDNA (8).

In addition to RAGE, our previous study also identified an LF-L AGE-binding protein in bovine lung extracts that bound AGEs (10). This polypeptide was termed the LF-L AGE-binding protein because of identity of the amino terminal sequence to lactoferrin, identical mobility on SDS-PAGE, cross-reactivity of the respective antisera, and comparable AGE binding activity of LF-L and lactoferrin. Western blotting of detergent extracts of MPs with anti-LF-L AGE-binding protein IgG demonstrated a single band with a relative molecular mass of $\approx 30$ $\mathrm{kD}$ (Fig. $1 B$, lane 1 ). This band migrates more rapidly than the purified bovine LF-L AGE-binding protein isolated from lung, which has a relative molecular mass $\approx 80 \mathrm{kD}$ (Fig. $1 \mathrm{~B}$, lane 2). In contrast, purified RAGE could not be visualized with anti-LF-L IgG (lane 3). Appearance of the bands from MPs and lung (lanes 1 and 2) was due to the presence of antigenic determinants in LF-L AGE-binding protein from lung, as addition of excess soluble LF-L (the purified $80-\mathrm{kD}$ polypeptide form) prevented visualization of this material (lanes 4 and 5 ). In contrast, addition of excess RAGE did not diminish the intensity of bands immunoreactive with the anti-LF-L AGEbinding protein antibody (data not shown). The presence of a more rapidly migrating band in extracts of MPs that reacts with anti-LF-L IgG is consistent with previous observations in which Western blotting of bovine endothelial extracts also showed a more rapidly migrating band with a relative molecular mass $\approx 30 \mathrm{kD}(10)$. Although the mechanism(s) leading to formation of this material is at present uncertain, it could arise from proteolytic cleavage of lactoferrin or LF-L $(27,28)$.

To establish that RAGE and the $30-\mathrm{kD}$ form of LF-L were distinct molecular entities, detergent extracts of MPs were adsorbed with either affinity-purified anti-LF-L IgG or antiRAGE IgG coupled to a solid support (Fig. $1 C$ and $D$ ). When the MP lysate was adsorbed with immobilized anti-RAGE IgG, Western blotting with anti-RAGE IgG revealed (Fig. $1 C$ ) that the band corresponding to RAGE disappeared in the passthrough (lane 1) whereas incubation of anti-RAGE IgG resin with high salt ( $\mathrm{NaCl}, 1 \mathrm{M}$ ) eluted RAGE (lane 3). Complementary results were obtained when MP lysates were incubated with immobilized anti-LF-L IgG and immunoblotted with anti-RAGE IgG; the band corresponding to RAGE remained present in the pass-through (lane 2) but not in the eluate of the anti-LF-L IgG affi-gel (lane 4). Western blotting of the same samples with anti-LF-L IgG (Fig. $1 D$ ) demonstrated disappearance of the band corresponding to LF-L in the pass-through of anti-LF-L IgG-affi-gel (lane 1) and appearance of this band in the eluate of the same resin (lane 3). Anti-LF-L IgG visualized a band corresponding to LF-L in the pass-through of antiRAGE IgG-affi-gel (lane 2) and its absence in the eluate from the same resin (lane 4). These data establish that RAGE and LF-L derived from MP detergent extracts are distinct molecular entities.

Immunofluorescence studies of nonpermeabilized human MPs to determine if RAGE and LF-L were present on the cell surface (Fig. 2) revealed a diffuse pattern of surface staining with anti-RAGE and anti-LF-L antibody (Fig. 2, $B$ and $C$, respectively) as compared with nonimmune IgG controls (Fig. $2 A)$.

$R A G E$ and the LF-L AGE-binding protein mediate the binding and internalization of ${ }^{125} I-A G E$-albumin. In view of the presence of RAGE and LF-L on the surface of human MPs, we considered whether they could mediate the interaction with soluble AGEs. ${ }^{125} \mathrm{I}-\mathrm{AGE}$-albumin bound to MPs at $4^{\circ} \mathrm{C}$ in a dose-dependent manner, $K \mathrm{~d} \approx 80 \mathrm{nM}$ (Fig. $3 A$ ) comparable
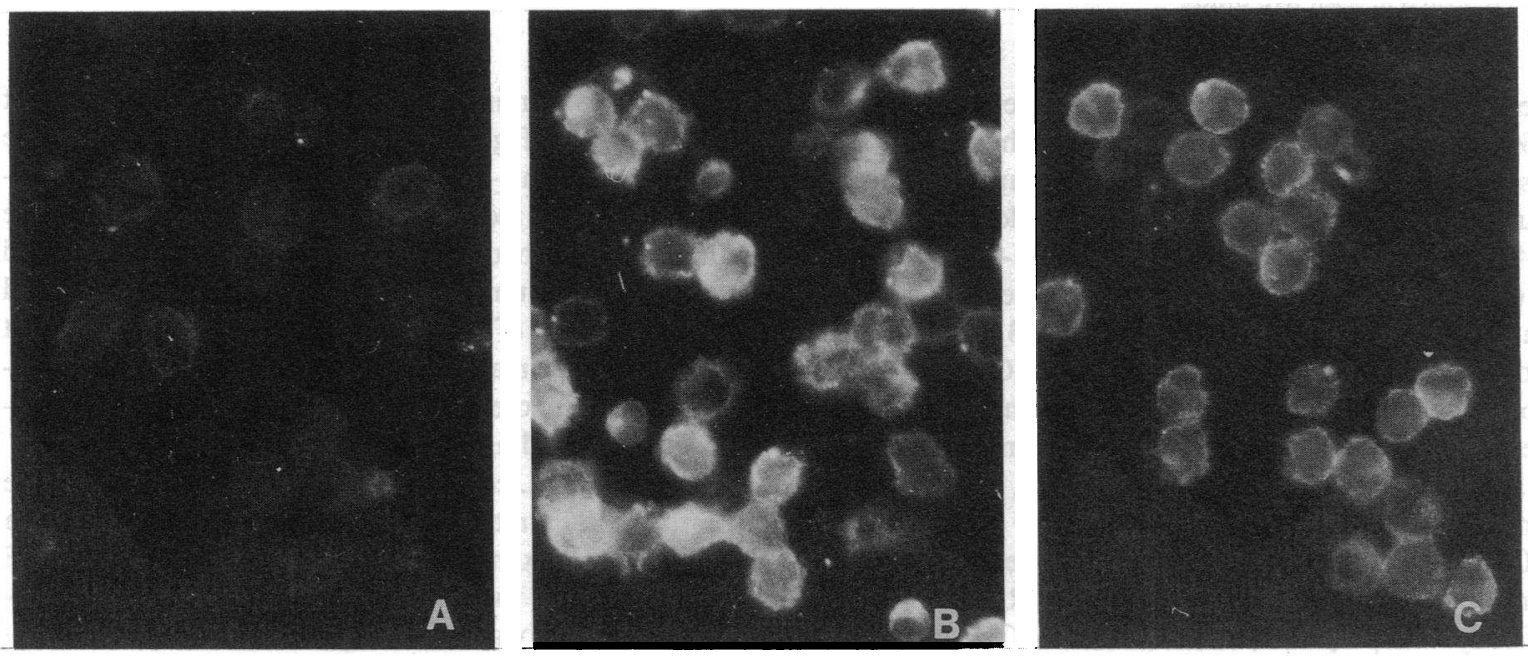

Figure 2. Detection of AGE-binding proteins on mononuclear phagocytes by indirect immunofluorescence. MPs were stained with nonimmune guinea pig $\operatorname{IgG}(A)$, anti-RAGE $\operatorname{IgG}(B)$, or anti-LF-L IgG $(C)$ as described in the text. $\times 650$. These experiments were repeated at least three times. 

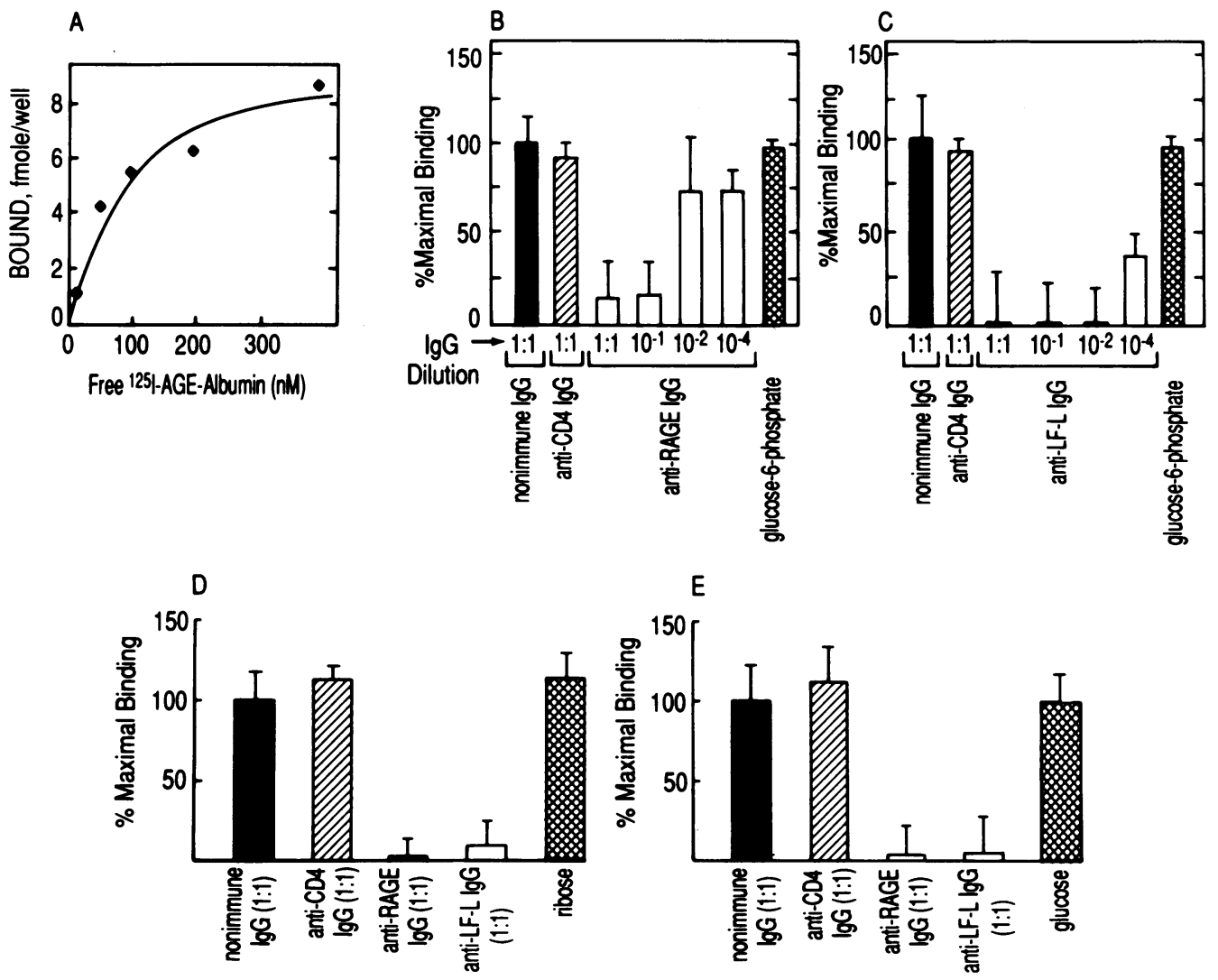

Figure 3. MP binding ${ }^{125}$ I-AGE albumin prepared by incubating albumin with either glucose6-phosphate $(A-C)$, ribose $(D)$, or glucose $(E)$ : effect of anti-RAGE and antiLF-L IgG. $(A)$ MPs were incubated with the indicated concentration of 125I-AGE-albumin alone (total binding) or in the presence of a 20-fold molar excess of unlabeled AGE-albumin (nonspecific binding) at $4^{\circ} \mathrm{C}$ for $3 \mathrm{~h}$. Cells were then washed, and cell-bound ${ }^{125}$ I-AGE-albumin was eluted with heparin-containing buffer. Specific binding (total minus monspecific binding) is plotted vs. concentration of free/added ${ }^{125} \mathrm{I}$-AGE albumin. Data were analyzed by nonlinear leastsquares analysis and parameters of binding are: $K_{\mathrm{d}}=82 \pm 24 \mathrm{nM}$, and $n$ $=10 \pm 1 \mathrm{fmol}$ of ligand bound per well at satura-

tion. $(B)$ MPs were preincubated with the indicated dilution of anti-RAGE IgG ( $1: 1$ dilution $=2.8 \mathrm{mg} / \mathrm{ml})$, anti-CD4 IgG $(1: 1$ dilution $=2.7$ $\mathrm{mg} / \mathrm{ml})$, or nonimmune $\mathrm{IgG}(1: 1=2.7 \mathrm{mg} / \mathrm{ml})$ for $2 \mathrm{~h}$ at $4^{\circ} \mathrm{C}$, and then a radioligand binding assay was performed at $4^{\circ} \mathrm{C}$ employing ${ }^{125} \mathrm{I}-$ AGE-albumin alone ( $100 \mathrm{nM}$ ) or in the presence of a 20-fold excess of unlabeled AGE-albumin. Maximal specific binding (100\%), defined in the presence of nonimmune IgG (1:1), was binding observed in wells incubated with ${ }^{125} \mathrm{I}$-AGE-albumin alone minus binding observed in wells incubated with ${ }^{125} \mathrm{I}-\mathrm{AGE}$-albumin in the presence of unlabeled material. Results shown are the mean $\pm \mathrm{SE}$ of at least quadruplicate determinations. The far right bar depicts the effect of adding excess glucose-6-phosphate $(25 \mathrm{mM})$ on the observed binding. $(C)$ MPs were preincubated with the indicated dilution of anti-LF-L IgG $(1: 1=2.5 \mathrm{mg} / \mathrm{ml})$, anti-CD4 $\operatorname{IgG}(1: 1=2.7 \mathrm{mg} / \mathrm{ml})$, or nonimmune $\operatorname{IgG}(1: 1=2.7 \mathrm{mg} / \mathrm{ml})$ and the assay was carried out as in $B$, above. The far right bar depicts the effect of adding excess glucose-6-phosphate (25 mM) on the observed binding. $(D)$ MPs were preincubated with 1:1 dilutions of antibodies as above, and the radioligand binding assay was performed in the presence of ${ }^{125} \mathrm{I}$-AGE albumin $(100 \mathrm{nM})$ prepared by incubating ribose with albumin. The far right bar depicts the effect of adding excess ribose ( 25 $\mathrm{mM}$ ) on the observed binding. $(E)$ MPs were preincubated with 1:1 dilutions of antibodies as above and AGE albumin (100 nM) was prepared by incubating glucose with albumin. The far right bar depicts the effect of adding excess of glucose ( $25 \mathrm{mM})$ on the observed binding. The experiments were repeated at least five times.

to what has been previously reported (29). The latter experiment used AGE-albumin prepared with glucose-6-phosphate, but similar results were obtained with glycated albumin prepared with glucose or ribose (data not shown). Addition of antibody to RAGE largely blocked the binding of ${ }^{125}$ I-AGE-albumin to MPs (Fig. $3 B$ ); this was true with ${ }^{125}$ I-glucose-6-phosphate albumin (Fig. $3 \mathrm{~B}$ ), ${ }^{125} \mathrm{I}$-ribose albumin (Fig. $3 \mathrm{D}$ ), and ${ }^{125}$ I-glucose albumin (Fig. $3 E$ ). Inhibition of ${ }^{125} \mathrm{I}-\mathrm{AGE}$-albumin binding to MPs was a specific effect of the immune IgG, as it was not observed with the same amount of nonimmune IgG or antibody to another MP surface protein, CD4 (Fig. 3, $B-E$ ). High concentrations of antibody were required for effective blocking of ${ }^{125} \mathrm{I}$-AGE-albumin-monocyte binding, presumably because of immunologic differences between bovine RAGE ( to which the antibody was prepared) and human RAGE (with which the antibody is reacting on human MPs).

Antibody to the LF-L AGE-binding protein also inhibited the binding of ${ }^{125} \mathrm{I}-\mathrm{AGE}-$ albumin to MPs at $4^{\circ} \mathrm{C}$ (Fig. 3, $C-E$ ) using glycated albumin prepared in the presence of glucose-6-phosphate (Fig. $3 C$ ), ribose (Fig. $3 D$ ), or glucose (Fig. $3 E$ ). As with anti-bovine RAGE IgG, high concentrations of antibody were required for maximal inhibition. These data indicate that antibodies raised to bovine lung RAGE and LF-L react with their human counterparts and that RAGE and LF-L mediate binding of ${ }^{125} \mathrm{I}$-AGE-albumin to human MPs at $4^{\circ} \mathrm{C}$. In all cases the unlabeled aldose sugars (glucose-6-phosphate, ribose, or glucose alone) did not compete with ${ }^{125} \mathrm{I}$ AGE-albumin for binding to MPs (Figs. 3, $B-E$ ).

If RAGE and LF-L comprise the MP surface binding site for AGEs, they should mediate the binding and internalization of AGEs at $37^{\circ} \mathrm{C}$. To examine these issues, cell-associated AGE albumin was localized to a cell surface or an internalized/endocytosed pool. Radioligand binding experiments with ${ }^{125} \mathrm{I}$ AGE albumin (prepared with glucose-6-phosphate) and MPs at $4^{\circ} \mathrm{C}$ demonstrated comparable elution of specifically bound radioactivity by exposure of cells to acidic buffer, heparin, dex- 

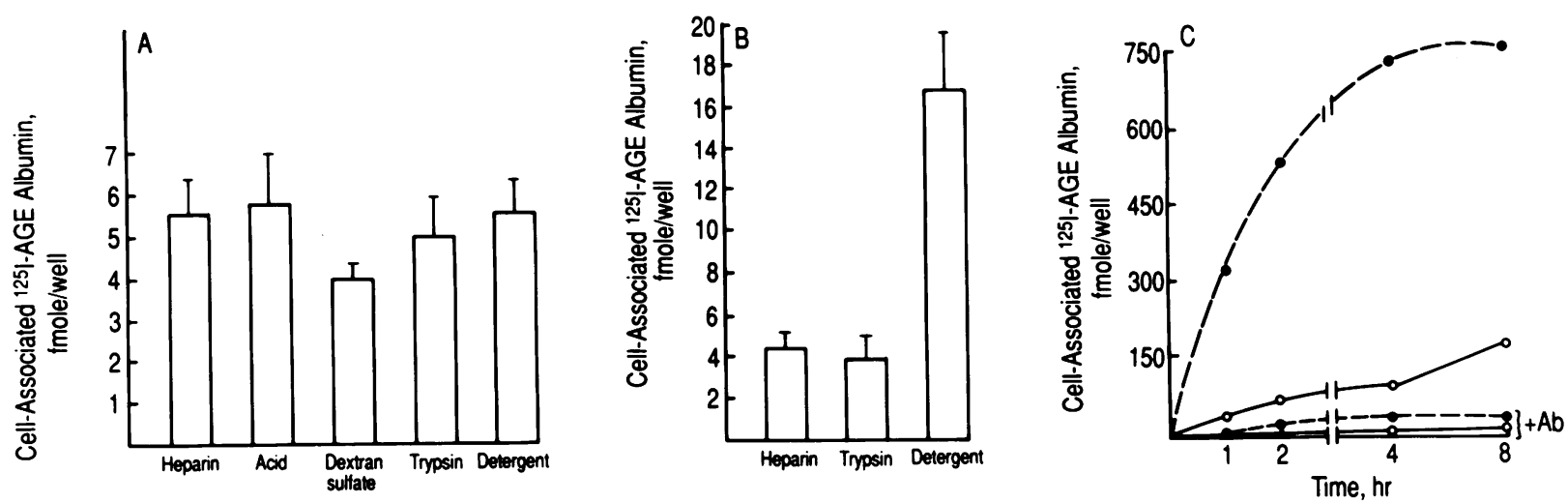

Figure 4. Cell-associated ${ }^{125} \mathrm{I}$-AGE-albumin (prepared by incubating albumin with glucose-6-phosphate) is bound to the cell surface at $4^{\circ} \mathrm{C}(A)$ and internalized $37^{\circ} \mathrm{C}(B$ and $C)$ via interaction with RAGE and LF-L. $(A)$ MPs were incubated with ${ }^{125} \mathrm{I}-\mathrm{AGE}$ albumin $(100 \mathrm{nM})$ at $4{ }^{\circ} \mathrm{C}$ for $3 \mathrm{~h}$, cultures were washed, and cell-associated radioligand was dissociated by exposure to buffer containing heparin, acid, dextran sulfate, trypsin, or detergent (Nonidet P-40), as described in the text. Results shown are the mean \pm SE of at least quadruplicate determinations. $(B)$ MPs were incubated with ${ }^{125} \mathrm{I}-\mathrm{AGE}$ albumin $(100 \mathrm{nM})$ at $37^{\circ} \mathrm{C}$ for $3 \mathrm{~h}$. After washing, cell-bound ${ }^{125} \mathrm{I}$-AGE albumin was eluted with buffer containing either heparin or trypsin, followed by detergent, as described in the text. Results shown are the mean $\pm \mathrm{SE}$ of at least quadruplicate determinations. (C) MPs were incubated with ${ }^{125} \mathrm{I}$-AGE-albumin alone ( $100 \mathrm{nM}$; total binding) or in the presence of 20-fold molar excess of unlabeled AGE-albumin (nonspecific binding) for the indicated times at $37^{\circ} \mathrm{C}$. As indicated (+Ab), immune IgG to both RAGE and LF-L (final concentration of each, 1.4 and $1.35 \mathrm{mg} / \mathrm{ml}$, respectively) were preincubated with MPs for $1 \mathrm{~h}$ at $4^{\circ} \mathrm{C}$. Then cultures were washed, and surface-bound radioactivity was eluted with heparin-containing buffer (solid lines), and internalized radioactivity (dashed lines) was determined by subsequent detergent solubilization of the cultures. Data shown represent specific binding (total minus nonspecific binding), the mean of duplicate determinations. Nonimmune IgG at the same concentration as anti-AGE-binding protein IgGs had no effect on ${ }^{125}$ I-AGE-albumin binding/internalization by MPs in this assay. The experiments were repeated at least two times.

tran sulfate, trypsin, or detergent (Fig. $4 \mathrm{~A}$ ). At $37^{\circ} \mathrm{C}$ (Fig. $4 \mathrm{~B}$ ) incubation of MPs with ${ }^{125}$ I-AGE-albumin also led to the formation of a cell surface-associated pool of cell-bound radioli-
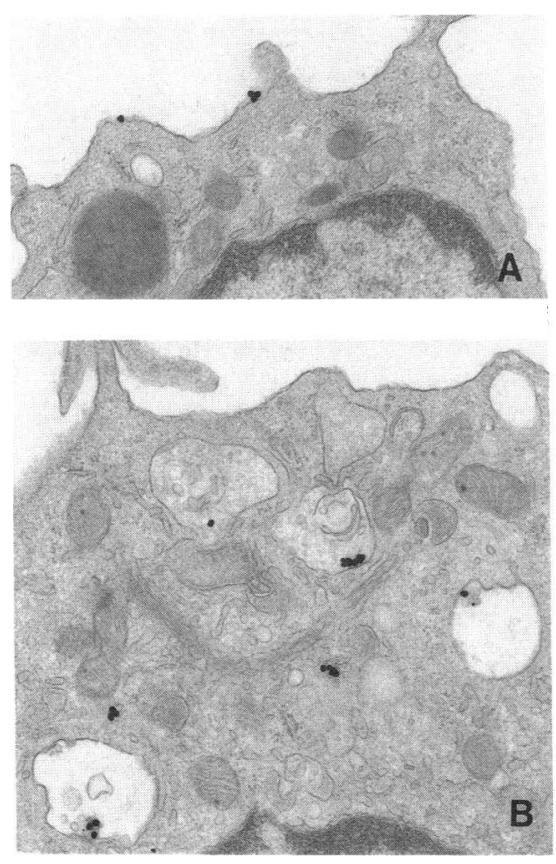

Figure 5. Binding and uptake of AGE albumin conjugated to colloidal gold particles by MPs. Incubation of MPs with colloidal gold ( 25 $\mathrm{nm})$ conjugated to $\mathrm{AGE}$ albumin $(500 \mathrm{nM})$ at $37^{\circ} \mathrm{C}$ results in binding to the cell surface $(A)$ and subsequent internalization via endocytosis, where it is localized to membrane-bound vesicles and components of the lysosomal compartment $(B) . \times 19,000$. The experiment was repeated twice. gand that could be eluted by exposure of cultures to buffer containing heparin or trypsin treatment. However, at the higher temperature, there was an additional pool of specifically cell-associated radioligand that remained after elution with heparin or trypsin (Fig. $4 \mathrm{~B}$ ) and was not observed in experiments performed at $4^{\circ} \mathrm{C}$ (at the lower temperature, the pool of ${ }^{125} \mathrm{I}$ AGE-albumin released from the cell by heparin, trypsin, or detergent coincided exactly). This additional cell-associated ${ }^{125}$ I-AGE-albumin observed at $37^{\circ} \mathrm{C}$ was released by dissolution of the cells in detergent-containing buffer. Ultrastructural studies with AGE-albumin colloidal gold conjugates confirmed that at $37^{\circ} \mathrm{C}$ a pool of ligand was present on the cell surface (Fig. $5 \mathrm{~A}$ ) from which it could be eluted with any of the treatments described above, as well as a pool of internalized ligand (Fig. $5 \mathrm{~B}$ ). The latter was found in membrane-bound vesicles and these internalized AGE-albumin gold conjugates were eluted by dissolution of the cells in detergent (data not shown).

On the basis of this analysis of the localization of cell-associated AGE-albumin, studies were performed to determine if anti-RAGE IgG and anti-LF-L IgG would block binding of ${ }^{125} \mathrm{I}$-AGE-albumin to MPs at $37^{\circ} \mathrm{C}$. Preincubation of MPs with simultaneously added anti-RAGE IgG and anti-LF-L IgG at $4^{\circ} \mathrm{C}$ blocked surface binding of ${ }^{125} \mathrm{I}-\mathrm{AGE}$ albumin at $37^{\circ} \mathrm{C}$ (Fig. $4 \mathrm{C}$ ), defined in this experiment as heparin-elutable radioactivity. The presence of antibodies to the AGE-binding proteins also prevented formation of the pool of endocytosed radioactivity (Fig. $4 \mathrm{C}$ ), defined as cell-associated material remaining after elution of surface-bound ${ }^{125}$ I-AGE-albumin.

Soluble AGE-albumin induces chemotaxis of MPs through interaction of $A G E$-moieties with RAGE and the LF-L AGEbinding protein. In view of the deposition of AGEs in the vasculature and the hypothesis that they could contribute to the pathogenesis of vessel wall lesions ( 1 ), we sought to understand 
mechanisms underlying their effect on MP migration. Our previous work has shown that soluble AGE-albumin (6) as well as other AGE-modified proteins induced chemotaxis of MPs, leading us to compare the effects of glycated albumin prepared with glucose-6-phosphate, glucose, or ribose (Fig. 6, $A-C$, respectively) on monocyte migration. Checkerboard analysis demonstrated that each of the glycated albumin preparations induced MP chemotaxis over a similar range of concentrations. When the sugars used for glycation were placed in the lower compartment of the chemotaxis chamber, they did not induce MP migration (Fig. $6, A-C$, top-most bar). Similarly, native albumin was devoid of MP chemotactic activity.

These experiments demonstrated that albumin glycated in the presence of glucose-6-phosphate, glucose, or ribose in vitro was chemotactic for MPs. To determine if these results could be extrapolated to glycated proteins that formed in vivo, AGEs from diabetic plasma, which was positive for AGE antigen by ELISA, were purified by immunoaffinity chromatography with antibody selective for the AGE-moiety linked to affi-gel. These patient-derived AGEs also induced MP chemotaxis (Fig. $6 \mathrm{D}$ ). When plasma from young healthy individuals was subjected to the same purification procedure, negligible AGE-immunoreactive material/protein was obtained and no MP chemotactic activity was observed (data not shown).

Our next goal was to determine whether RAGE and LF-L were involved in mediating MP migration in response to
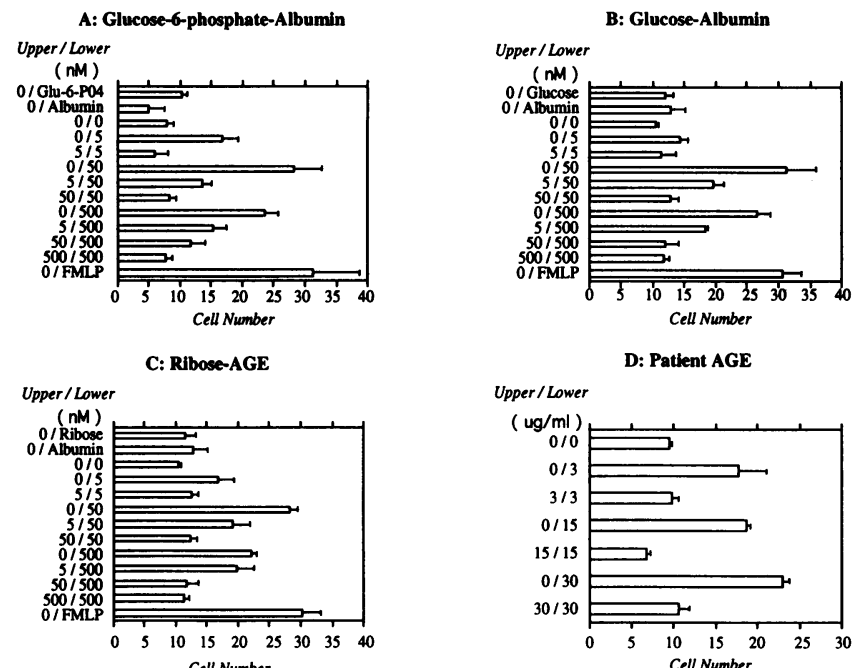

Figure 6. Effect of soluble AGEs on MP chemotaxis: experiments with AGEs prepared by incubating albumin with either glucose-6-phosphate $(A)$, glucose $(B)$, ribose $(C)$, or AGEs derived from diabetic patient plasma $(D)$. The indicated concentration of AGE albumin $(\mathrm{nM})(A-C)$ or AGEs from diabetic plasma $(\mu \mathrm{g} / \mathrm{ml})$ was added to either the upper or lower compartment of the chemotaxis chamber, MPs were added to the upper compartment and the migration assay was performed as described in the text. The upper line in $A-C$ demonstrates the results when either glucose-6-phosphate (Glu-6-PO4), glucose, or ribose, respectively, was added to the lower compartment of the chamber at a concentration of $250 \mathrm{mM}$. Positive controls employed FMLP $\left(10^{-6} \mathrm{M}\right)$ added to the lower compartment. The $x$-axis represents the average number of cells in nine high-powered fields that had migrated across the membrane. The mean \pm SEM of triplicate determinations is shown and the experiments were repeated at least 3 times.
AGEs. When MPs were preincubated with anti-RAGE IgG at $4^{\circ} \mathrm{C}$, washed, warmed to $37^{\circ} \mathrm{C}$, and then placed in the upper compartment of the chemotaxis chamber, the migratory response to glucose-6-phosphate-albumin was blocked in a dosedependent manner (Fig. $7 A$ ). Migration of MPs in response to soluble glucose-albumin, ribose-albumin, or patient-derived AGEs was also blocked by anti-RAGE IgG (Fig. $7, B-D$, respectively). $\mathrm{F}\left(\mathrm{ab}^{\prime}\right)_{2}$ fragments prepared from anti-RAGE IgG had a similar inhibitory effect on MP chemotaxis to AGE-albumin (Fig. $7 \mathrm{~A}$ ), though neither anti-RAGE IgG nor the $\mathrm{F}\left(\mathrm{ab}^{\prime}\right)_{2}$ fragments altered migration in response to FMLP (Fig. $7 A$ ).
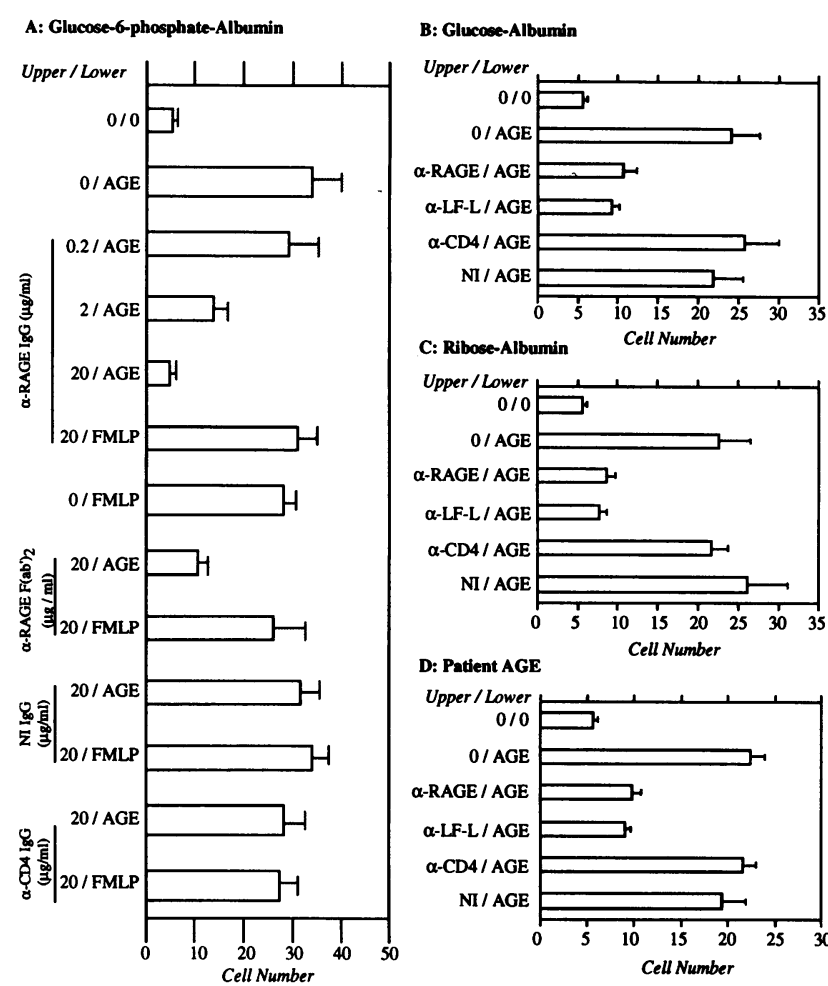

$$
\alpha-
$$

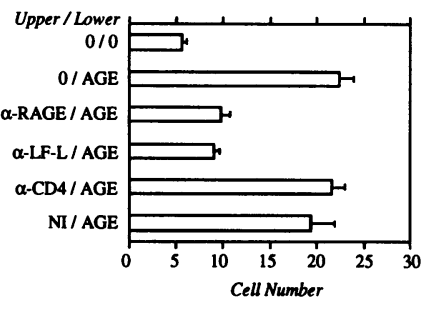

Figure 7. Effect of anti-AGE-binding protein IgG on MP chemotaxis induced by soluble AGE/glycated albumin prepared by incubating albumin with either glucose-6-phosphate $(A)$, glucose $(B)$, ribose $(C)$, or AGEs derived from diabetic plasma $(D)$. $(A)$ MPs freshly harvested from human blood were suspended $\left(10^{6}\right.$ cells $\left./ \mathrm{ml}\right)$ in RPMI 1640 containing fetal bovine serum ( $1 \%)$ and preincubated with the indicated concentration of anti-RAGE IgG or $\mathrm{F}\left(\mathrm{ab}^{\prime}\right)_{2}$, nonimmune $\operatorname{IgG}(N I)$, or anti-CD4 IgG $(\alpha-C D 4)$ for $1 \mathrm{~h}$ at $4^{\circ} \mathrm{C}$ were washed twice in balanced salt solution, and then $10^{4}$ cells were added to the upper wells of chemotaxis chambers. MP migration was initiated by adding either soluble AGE-albumin (AGE; $50 \mathrm{nM}$ ) or FMLP $\left(10^{-6} \mathrm{M}\right.$ ) to the lower well as the chemotactic stimulus. Chambers were incubated at $37^{\circ} \mathrm{C}$ in a humidified atmosphere for $4 \mathrm{~h}$, and then membranes were washed, fixed in methanol, and Wright stained. The $x$-axis represents the average number of cells in nine high-powered fields that had migrated across the membrane. The mean \pm SEM of triplicate determinations is shown. $(B-D)$ Experiments were performed according to the same protocol as above $(A)$ in which the stimulus for MP migration was AGE albumin prepared in the presence of glucose $(B)$, ribose $(C)$, or AGEs derived from patient plasma $(D)$. The concentration of AGEs prepared in vitro was $50 \mathrm{nM}(A-C)$ and the concentration of patient-derived AGEs was $30 \mu \mathrm{g} / \mathrm{ml}(D)$. The antibodies were employed at a concentration of $20 \mu \mathrm{g} / \mathrm{ml}$. The experiments were repeated at least three times. 


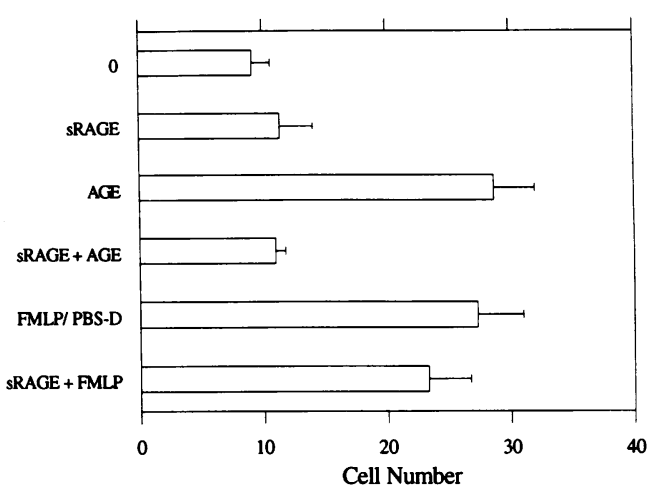

Figure 8. Effect of sRAGE on MP chemotaxis induced by soluble AGE-albumin (prepared in the presence of glucose-6-phosphate). sRAGE $(25 \mu \mathrm{M})$ was preincubated with AGE-albumin $(250 \mathrm{nM})$ or FMLP $(1 \mu \mathrm{M})$ for $1 \mathrm{~h}$ at $37^{\circ} \mathrm{C}$, and then the reaction mixture was added to the lower compartment of the chemotaxis chamber. Controls included experiments performed with either sRAGE alone or the buffer in which SRAGE was dissolved (PBS containing octyl- $\beta$ glucoside, $0.01 \%$ or PBS-D) or FMLP $\left(10^{-6} \mathrm{M}\right)$. The response to FMLP $\left(10^{-6} \mathrm{M}\right)$ alone was comparable to that observed with FMLP + PBS-D or sRAGE. The chemotaxis assay was performed and assessed as in Figs. 6 and 7 above. These experiments were performed at least three times.

Control experiments with nonimmune IgG and polyclonal IgG to CD4 in place of antibodies to RAGE and LF-L had no effect on MP migration in response to AGE-albumin (Fig. 7, $A-D$ ).

These observations suggested that interaction of AGEs with monocyte RAGE was necessary to initiate chemotaxis in response to soluble AGE-albumin. Supporting this hypothesis, addition of soluble RAGE, which should block interaction of AGEs with their receptors on the surface of MPs, prevented AGE-induced migration (Fig. 8). For this experiment, excess sRAGE was preincubated with AGE-albumin for $1 \mathrm{~h}$ at $37^{\circ} \mathrm{C}$, the mixture was added to the lower compartment of the chemotaxis chamber, and subsequent migration of MPs in response to soluble AGE-albumin was blocked. In contrast,
sRAGE had no effect on the migration of MPs in response to the chemotactic stimulus FMLP (Fig. 8).

These data, which suggested a role for RAGE in mediating MP migration in response to AGE-albumin, led us to test the effect of preincubation of MPs with anti-LF-L IgG (Fig. 7, $B-D$ and Fig. 9). IgG to the LF-L AGE-binding protein also blocked MP migration to AGE-albumin prepared with glucose-6-phosphate in a dose-dependent manner (Fig. 9, lines $2-4)$. $F\left(a b^{\prime}\right)_{2}$ fragments prepared from anti-LF-L IgG had a similar inhibitory effect on MP migration (Fig. 9, line 7) whereas neither of these immunologic reagents altered MP migration to FMLP (Fig. 9, lines 5 and 8 , respectively). In addition, nonimmune IgG at the same concentration had no effect on MP migration in response to AGE-albumin or FMLP added to the lower compartment of the chemotaxis chamber (Fig. 9, lines 9 and 10 , respectively). Antibody to LF-L similarly inhibited MP chemotaxis in response to AGE-albumin glycated with glucose, ribose, or to AGEs derived from diabetic patient plasma (Fig. 7, $B-D$, line four in each case, respectively).

Taken together these observations are consistent with the hypothesis that access of the AGE ligand to RAGE and LF-L on the MP was required for MP migration to occur in response to soluble AGE-albumin. To explore further the nature of the ligand mediating chemotaxis, we found that preincubation of AGE-albumin, either preparations made by incubating albumin with glucose-6-phosphate, glucose, or ribose with albumin, with anti-AGE IgG blocked MP migration in a manner dependent on the antibody concentration used (Fig. 10, $A-C$, respectively). Anti-AGE antibody (Fig. $10 \mathrm{~A}$ ) and the same concentration of nonimmune IgG (designated NI, the second line in Fig. 10, $B-D$ ) had no effect on the migration of MPs in response to FMLP. In addition, the anti-AGE antibody blocked chemotaxis in response to AGEs purified from diabetic plasma (Fig. $10 \mathrm{D}$ ). This is consistent with our recent observations that the anti-AGE antibody blocked the binding of AGEs to cellular surfaces (Yan, S. D., A. M. Schmidt, J. Brett, and D. Stern, manuscript in preparation ).

Immobilized AGEs attenuate migration of MPs. Accumulation of MPs in the subendothelium is thought to have a central role in the development of the vascular lesions, such as

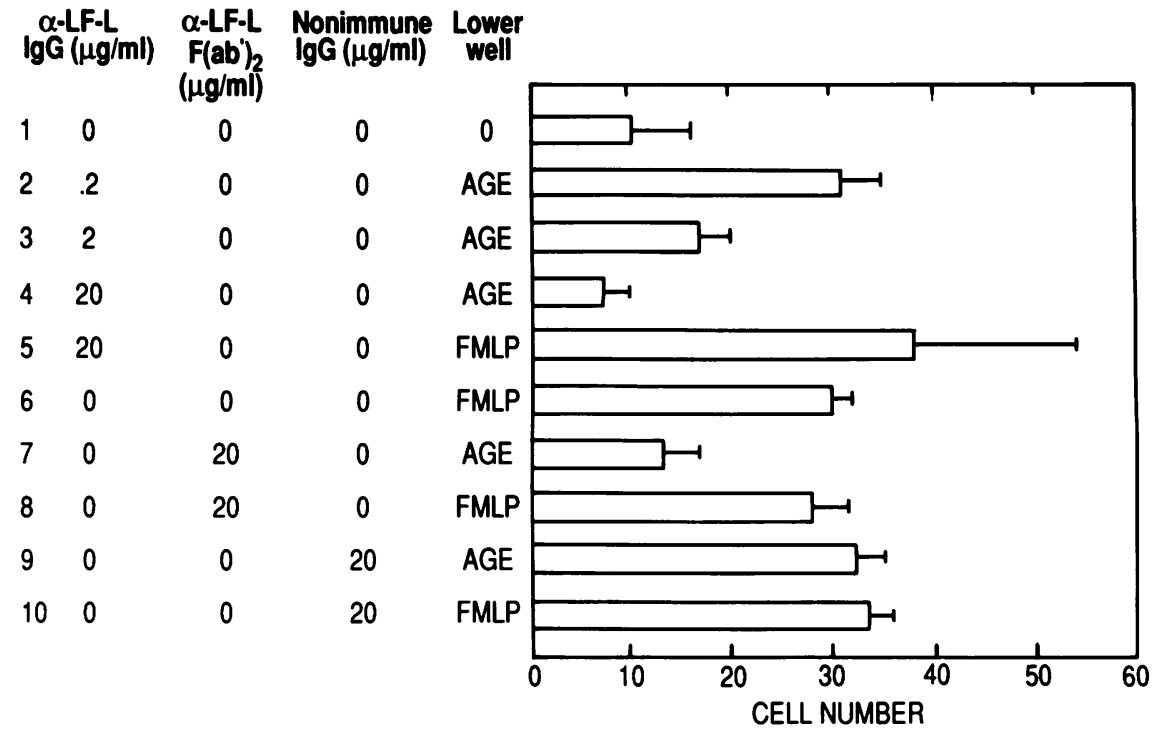

Figure 9. Effect of anti-LF-L IgG and $\mathrm{F}\left(\mathrm{ab}^{\prime}\right)_{2}$ on MP chemotaxis induced by AGE albumin (prepared in the presence of glucose-6-phosphate). The same experimental protocol was followed as in Figs. 6 and 7 above, except that anti-LF-L AGE-binding protein IgG or $\mathrm{F}\left(\mathrm{ab}^{\prime}\right)_{2}$ was used. These experiments were performed at least three times. The chemotactic response of MPs to glucose-6-phosphate albumin in the absence of antibodies was identical to the response observed with nonimmune IgG (line 9). 

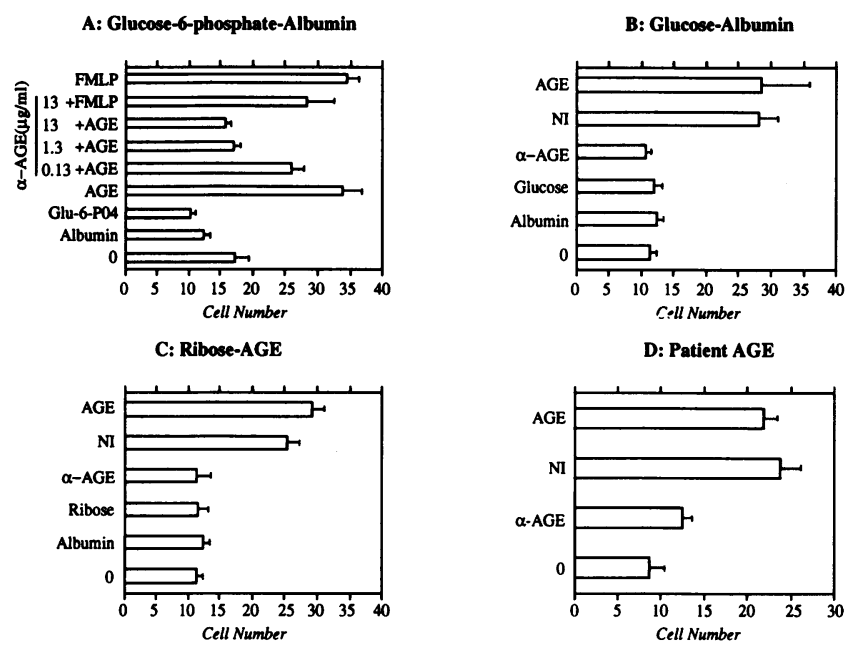

Figure 10. Effect of anti-AGE IgG ( $\alpha$-AGE) on the chemotactic response of human MPs to AGE albumin prepared by incubating albumin with glucose-6-phosphate $(A)$, glucose $(B)$, ribose $(C)$, or AGEs derived from diabetic patient plasma $(D) .(A)$ MPs were added to chemotaxis chambers containing AGE albumin ( $50 \mathrm{nM})$ alone or AGE albumin preincubated for $1 \mathrm{~h}$ at $37^{\circ} \mathrm{C}$ with the indicated concentration of anti-AGE IgG in the lower compartment. Positive controls employed FMLP $\left(10^{-6} \mathrm{M}\right)$ added to the lower compartment of the chamber. Chemotaxis assays were performed as described above. $(B-D)$ The same experiment was performed in $B$ and $C$ using albumin glycated in the presence of glucose $(B)$ or ribose $(C)$ at a final AGE albumin concentration of $50 \mathrm{nM}$. Antibodies, either anti-AGE $(\alpha-A G E)$ or nonimmune $(N I)$, each at a concentration of $13 \mu \mathrm{g} / \mathrm{ml}$, were added to the lower compartment of the chemotaxis chamber as above $(A)$. Native albumin ( $50 \mathrm{nM}$ ) and glucose or ribose (each at a concentration of $250 \mathrm{mM}$ ) were added to the lower compartment of the chamber as indicated. In $D$, the same experimental protocol was followed with AGEs derived from the diabetic plasma. These experiments were repeated two to three times.

atherosclerosis (30). For AGEs to contribute to the retention of MPs in the vasculature, under certain conditions, such as following their immobilization in the extracellular matrix, they would have to block migration of MPs. To test this, AGE-albu- min was immobilized on the upper surface of a membrane in a chemotaxis chamber and the migratory response of MPs to the stimulus FMLP ( the latter added to the bottom well) was studied (Fig. 11). For these and the other studies reported below results are reported only with AGE-albumin preparations prepared with glucose-6-phosphate, since the cellular interactions of glycated albumin preparations made with glucose-6-phosphate, glucose, or ribose, as well as patient-derived AGEs, appear to be comparable. When the upper surface of the chemotaxis chamber membrane was coated with native albumin, migration in response to FMLP occurred in a dose-dependent manner, with increasing numbers of MPs appearing in the lower chamber (Fig. 11, lines 1-4). In contrast, when AGE-albumin was adsorbed to the upper surface of the chemotaxis chamber membrane, MP migration in response to FMLP was considerably reduced (Fig. 11, lines 5-7).

To assess if the inhibitory effect of immobilized AGE-albumin on MP migration to FMLP was due to interaction of the ligand with AGE-binding proteins on the MP surface, the effect of antibodies to RAGE and LF-L was studied (Fig. 12). Preincubation of MPs with either anti-RAGE IgG (Fig. 12, line 6), anti-LF-L IgG (Fig. 12, line 7), or both of these immune IgGs (Fig. 12, line 8) increased MP migration to the lower chamber in response to FMLP. A similar inhibitory effect was observed with $\mathrm{F}\left(\mathrm{ab}^{\prime}\right)_{2}$ fragments derived from anti-RAGE IgG and antiLF-L IgG (Fig. 12, lines 9-11). Control experiments demonstrated that AGE-albumin, but not native albumin, had to be present on the upper surface of the chemotaxis chamber for arrest of MP migration in response to FMLP to occur (Fig. 12, lines 1-4). Furthermore, preincubation of MPs with nonimmune IgG (in place of anti-AGE-binding protein IgG) did not alter MP migration (Fig. 12, line 5). These results predict that interference with the interaction of the immobilized glycated proteins with the AGE-binding proteins would block the effect of AGEs. Consistent with this hypothesis, addition of sRAGE to the membranes coated with AGE-albumin restored chemotaxis in response to FMLP (Fig. 13).

These data suggested that when migrating MPs interact with immobilized AGEs their motion is slowed. Phagokinetic track assays (18) were performed to directly visualize MP mi-

\begin{tabular}{ccc} 
& \multicolumn{2}{c}{$\begin{array}{c}\text { Adsorbed to upper } \\
\text { surface of membrane }\end{array}$} \\
\cline { 2 - 3 } & AGE-albumin & Native albumin \\
1 & 0 & + \\
2 & 0 & + \\
3 & 0 & + \\
4 & 0 & + \\
5 & + & 0 \\
6 & + & 0 \\
7 & + & 0
\end{tabular}

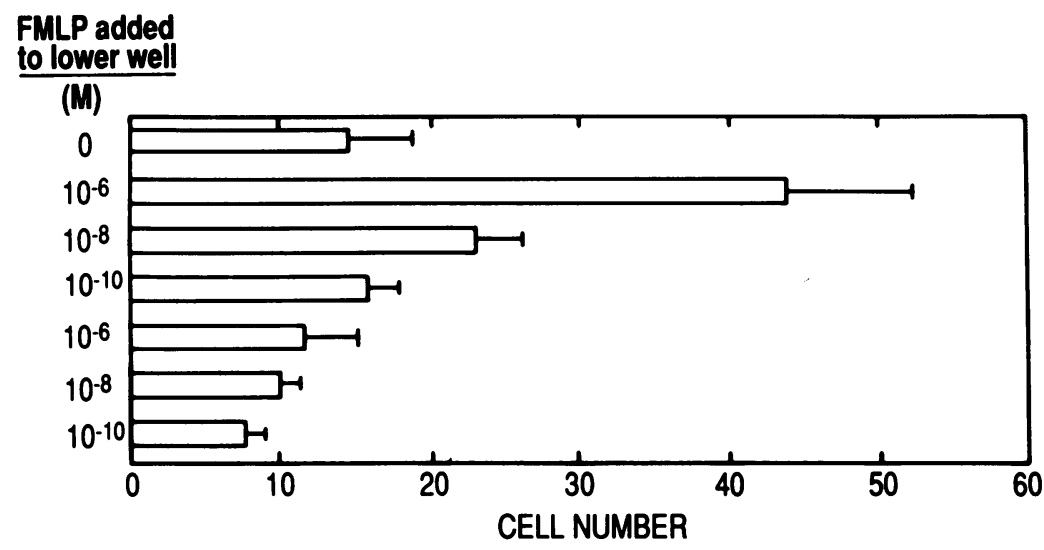

Figure 11. Effect of AGE albumin bound to the membrane in the chemotaxis chamber on MP migration in response to FMLP. Human MPs (10 4 cells per well) were placed in the upper wells of chemotaxis chambers in which the upper surface of the membranes had been coated with either AGE albumin (prepared in the presence of glucose-6-phosphate) or native albumin ( $500 \mathrm{nM}$ ). Then, the chemotactic peptide FMLP, at the indicated concentrations, was added to the lower compartment. The mean and SEM of quadruplicate determinations is shown and the experiments were repeated at least three times. 


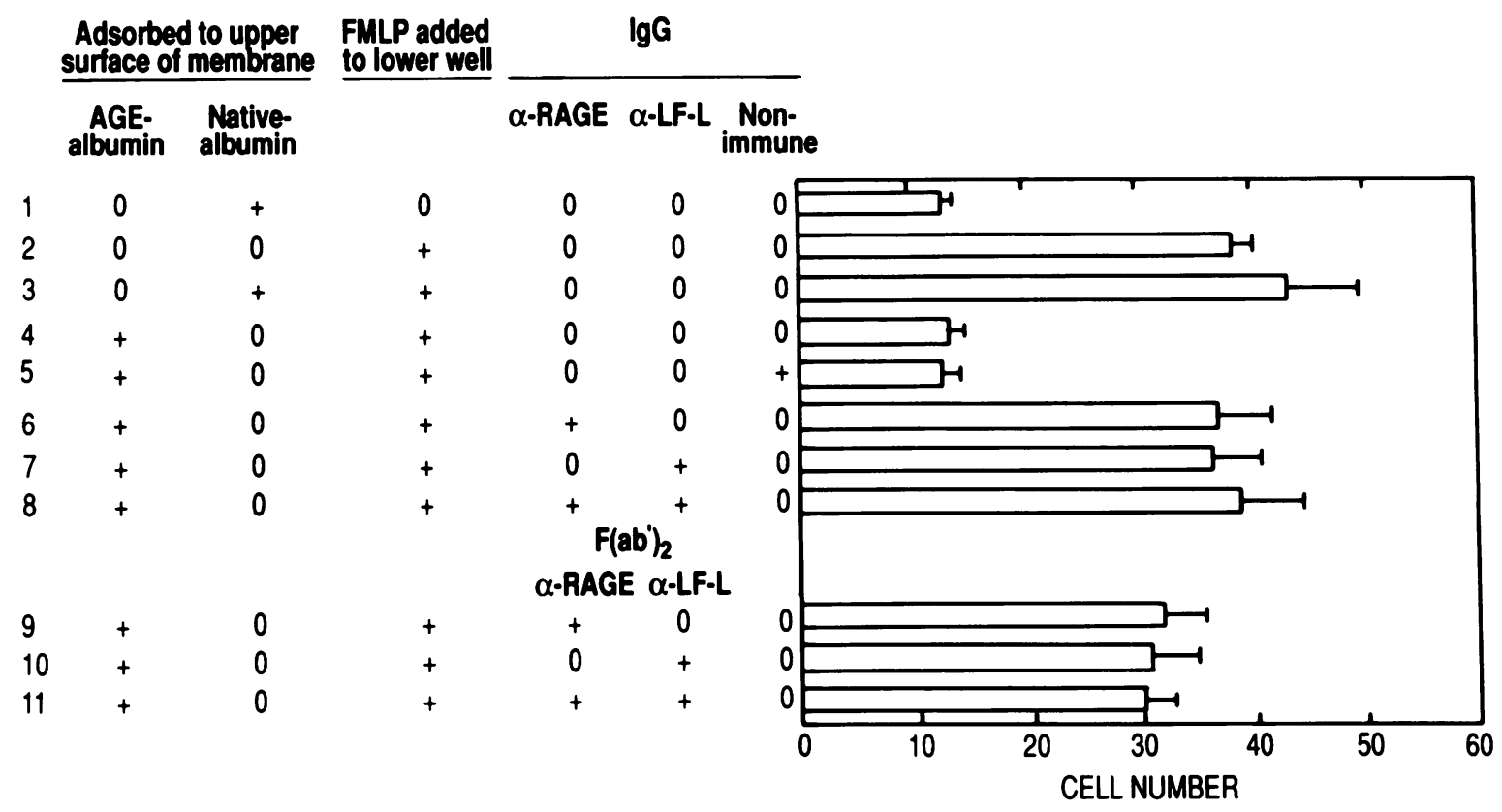

Figure 12. Antibodies to AGE-binding proteins restore the chemotactic response to FMLP in the presence of membranes coated with AGE albumin (prepared in the presence of glucose-6-phosphate). MPs were preincubated for $1 \mathrm{~h}$ at $4^{\circ} \mathrm{C}$ with either anti-RAGE $\mathrm{IgG}(20 \mu \mathrm{g} / \mathrm{ml})$, anti-LF-L $(20 \mu \mathrm{g} / \mathrm{ml}$ ), both antibodies together (anti-RAGE IgG, $20 \mu \mathrm{g} / \mathrm{ml}$; anti-LF-L IgG, $20 \mu \mathrm{g} / \mathrm{ml}$ ), or nonimmune IgG $(20 \mu \mathrm{g} / \mathrm{ml})$. Where indicated, $\mathrm{F}\left(\mathrm{ab}^{\prime}\right)_{2}$ fragments were used in place of IgGs at the same concentration. Cells were then washed in balanced salt solution and resuspended at the same cell density in RPMI 1640 containing fetal bovine serum (1\%). The chemotaxis assay was then performed by adding FMLP $\left(10^{-6} \mathrm{M}\right)$ to the lower well of the chambers and the experiments were repeated at least three times.

gration on an AGE-derivatized surface. When MPs were plated on coverslips coated with native albumin that had been overlaid with colloidal gold, long paths of migration were evident (Fig. $14 A$, left ). In contrast, when AGE-albumin was used in place of the native molecule, the tracks were much shorter (Fig. $14 \mathrm{~B}$, right). Experiments with coverslips coated with AGEcollagen I also showed a similar reduction in the length of MP tracks compared with controls with native collagen I (data not shown ).

In vivo model of $A G E$ deposition. PTFE tubes with adsorbed AGE-albumin or native albumin provide a surface which very slowly releases the proteins over days (Fig. 15 $A$ ). Thus, this system consists of both low concentrations of soluble protein dissociating from the mesh, in addition to the same proteins immobilized on the PTFE substrate. Subcutaneous placement of native albumin-PTFE tubes incited virtually no cellular response, except for some at the PTFE-tissue interface, seen after $4 \mathrm{~d}$ of implantation (Fig. $15 \mathrm{~B}$ ). In contrast, PTFE tubes with AGEs implanted for the same time incited a florid mononuclear cellular infiltrate: in Fig. $15 C$, mononuclear cells are shown moving through the interstices of the PTFE mesh. Many of the monocytes trapped within the PTFE mesh display leukoclastic changes at higher magnification (Fig. $15 \mathrm{D}$ ). After $8 \mathrm{~d}$ of implantation, a florid foreign body-type granulomatous response is seen primarily at the interface of PTFE tubes impregnated with native albumin (Fig. $15 \mathrm{E}$ ). PTFE tubes with

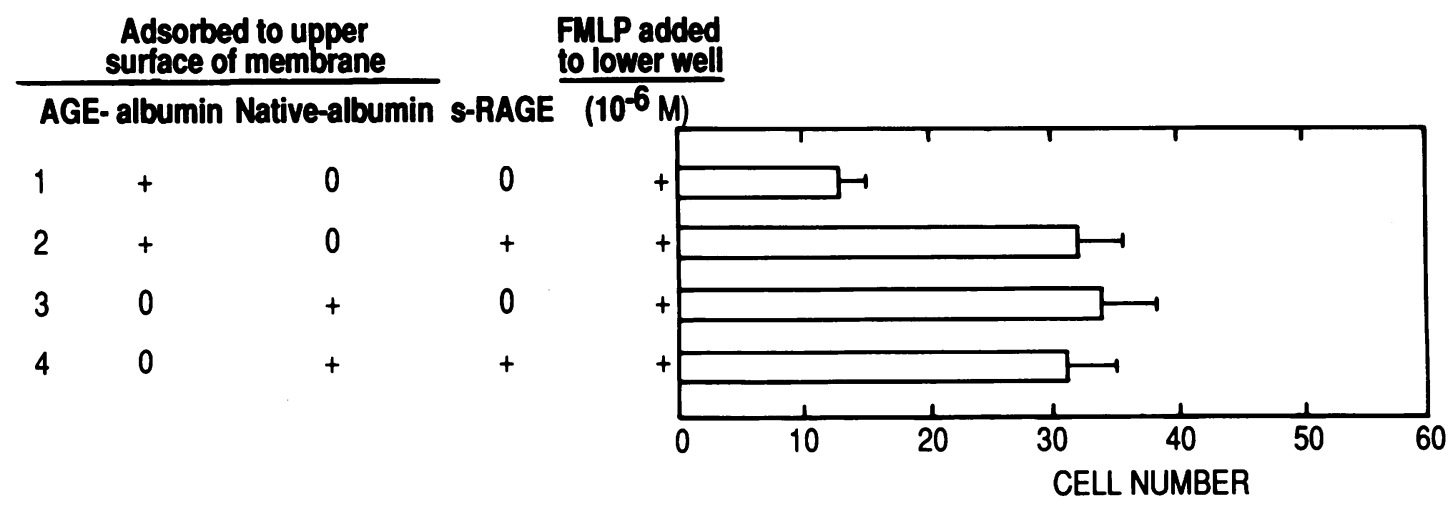

Figure 13. sRAGE restores the chemotactic response to FMLP in the presence of membranes coated with AGE albumin (prepared in the presence of glucose-6-phosphate). sRAGE ( 100 -fold molar excess over AGE coating the membrane surface) was incubated with membranes previously coated with native albumin or AGE albumin, and then a chemotaxis assay was performed as above with FMLP as the stimulus in the lower chamber. The mean \pm SEM of quadruplicate determinations is shown and the experiments were repeated at least three times. 

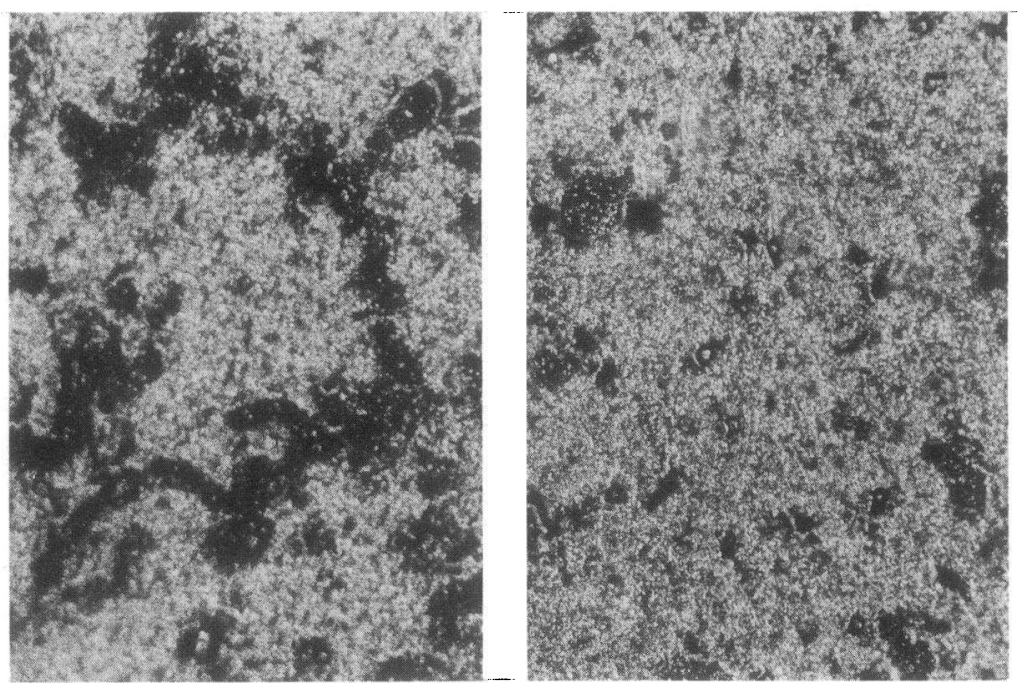

Figure 14. Phagokinetic track assay: MP migration on matrix composed of native albumin or AGE albumin (prepared in the presence of glucose-6-phosphate). MPs were allowed to migrate for $6 \mathrm{~h}$ on matrixes of native albumin or AGE-albumin (left and right, respectively) which had been coated with colloidal gold particles. The dark tracks left by locomoting MPs are visualized by dark-field microscopy. $\times 125$. The experiment was repeated at least three times.

adsorbed AGEs are filled with mononuclear cells (Fig. $15 F$ ), many of which show epithelioid changes (Fig. $15 G$ ).

\section{Discussion}

The results of our studies delineate a model ligand-receptor system that affects MP migration. The ligands are heterogeneous nonenzymatically glycated proteins termed AGEs. Similar binding of radioiodinated AGEs to the MP surface and modulation of monocyte migration was observed with AGEalbumin prepared by incubating albumin with glucose, glucose-6-phosphate, or ribose, as well as with AGEs purified from diabetic plasma. We have shown that there is a major difference, however, between the effects of soluble AGE-albumin, used as a prototypic compound for AGEs detected in blood (31), and AGE-albumin/AGE-collagen I adsorbed to substrates, used as models for insoluble AGEs immobilized on long-lived structures in the basement membrane. Soluble AGEs induce MP migration, presumably in response to a concentration gradient formed by diffusion from the lower compartment of the chemotaxis chamber. In contrast, immobilized AGEs slow monocyte migration, presumably through engagement of AGE receptors. This marked difference in the cellular response to soluble versus immobilized ligand may provide important insight into the contribution of AGEs to certain pathological situations in vivo. In the tissues, insoluble AGEs have been localized to extracellular matrixes, whereas only small amounts of soluble AGEs would be present, since most are cleared rapidly from the intravascular space $(11,32)$. Defective wound healing in genetically diabetic mice is due in part to a delayed and decreased early cellular response, including decreased migration of mononuclear phagocytes (33). This leads us to speculate that matrix-associated AGEs could attenuate MP migration into a wound, retarding subsequent cellular events promoting repair.

The cellular acceptor site for AGEs involves two polypeptides, RAGE and LF-L. Although the mode of association of these two proteins on the cell surface has not been clarified, recent studies demonstrating that LF-L binds to RAGE in a noncovalent high affinity fashion (34) suggest the following model: RAGE, an integral membrane protein, is anchored on the cell surface and interacts with LF-L from that site. In support of this hypothesis, antibodies to either RAGE or LF-L largely blocked the binding of ${ }^{125}$ I-AGE-albumin to human MPs (Figs. 3 and 4) and bovine endothelial cells (10). The concept of two closely associated cell surface AGE-binding proteins is also consistent with studies of Yang et al. (11) in a rat system, where antibodies to either one of two AGE-binding proteins blocked binding of AGE ligands. It should be noted that the sequence of the two AGE-binding proteins reported by Yang et al. (11) is different than RAGE and LF-L, indicating that they are likely to be distinct.

The central role of the cellular AGE-binding proteins in modulating MP chemotaxis in response to either soluble or immobilized AGE-albumin was shown in studies with specific antibodies to RAGE and LF-L as well as their $F\left(a b^{\prime}\right)_{2}$ fragments. Two additional lines of evidence suggest a close relationship between binding of AGEs to cell surface RAGE and LF-L and changes in MP migration: doses of AGE-albumin that stimulate chemotaxis are similar to those that result in occupancy of AGE-binding sites on MPs (Fig. 3 and Kirstein et al. [6]), and soluble RAGE, which blocks the interaction of AGEs with cellular surfaces (32), prevents the effects of AGEs on MP migration. Of note is that higher concentrations of antibody were required to block the binding of ${ }^{125} \mathrm{I}$-AGE-albumin to MPs compared with the concentrations of antibody required to inhibit AGE-stimulated MP migration. A possible explanation for the difference in concentrations of antibodies required to alter MP migration and binding of radiolabeled AGE-albumin might be that engagement of a limited number of receptors by either of the antibodies blocks ligand-induced activation of a critical (i.e., threshold) number of receptors. Further studies will be required to test this hypothesis.

The ability of AGEs to modulate MP migration indicates one way in which these glycated proteins might contribute to the pathogenesis of vascular lesions: soluble AGEs loosely bound to the vessel can attract AGEs to the vessel wall and immobilized matrix-associated AGEs in the subendothelium could retain MPs and lead to their activation $(6,7)$. This concept is supported by studies of Vlassara et al. (12) indicating that infusion of high concentrations of AGE-albumin leads to 

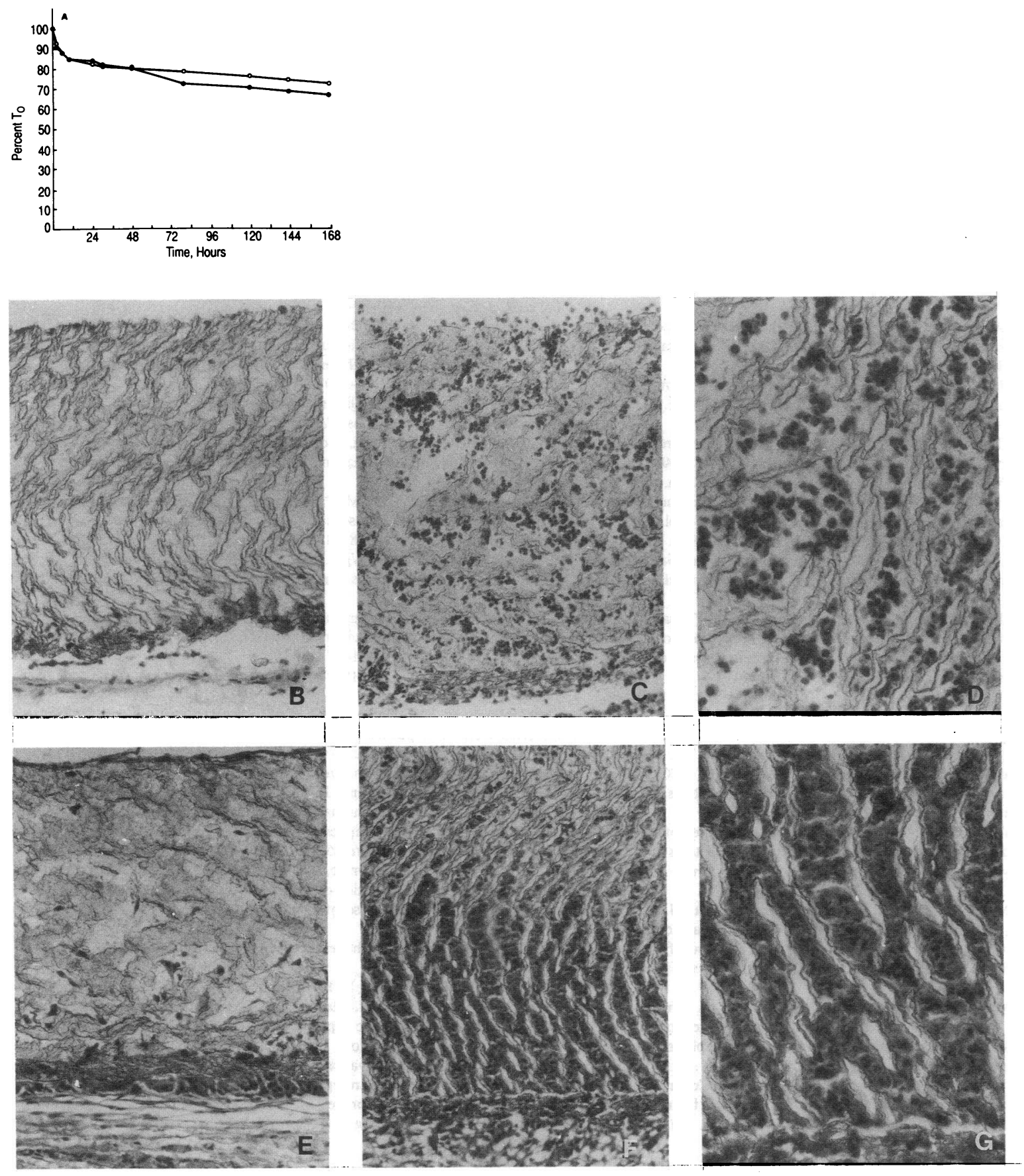

Figure 15. Implantation of PTFE tubes with adsorbed AGE albumin into rats. PTFE tubes were impregnated with either AGE albumin (prepared in the presence of glucose-6-phosphate) or native albumin as described in the text. In $A$, the protein solutions also contained trace amounts of ${ }^{125}$ I-AGE-albumin (closed circle) or ${ }^{125}$ I-native albumin (open circle). PTFE tubes were then incubated for the indicated times in saline and the percent of radiolabel remaining adsorbed compared with that present initially $\left(T_{0}\right)$, was determined. In $B-G$, PTFE tubes with adsorbed native albumin $(B, E)$ or AGE-albumin $(C$ and $D, F$ and $G)$ were implanted into the subcutaneous tissue of a rat. The tubes were removed after 4 $(B-D)$ or $8 \mathrm{~d}(E-G)$ and examined for the presence of infiltrating cells (hematoxylin and eosin staining). $D$ and $G$ are higher power views of fields from PTFE tubes impregnated with AGE-albumin implanted for 4 or $8 \mathrm{~d}$, respectively. $B$ and $C$ and $E$ and $F, \times 110 ; D$ and $G, \times 280$. The experiment was repeated three times.

infiltration of the vessel wall by MPs and by our studies showing that PTFE tubes impregnated with AGEs excite a florid cellular infiltrate by attracting and retaining mononuclear phagocytes (Fig. 15).

\section{Acknowledgments}

Dr. Seth Lederman generously provided antibody to CD4. We thank Mr. Samuel Rover for his generous gift. Drs. Gabriel Godman and 
Samuel C. Silverstein provided invaluable suggestions during the course of this work and critiques of the manuscript.

This work was supported by grants from the U.S. Public Health Service (HL-21006, HL-34625, HL-42833, HL-42507), New York Heart Association, Juvenile Diabetes Foundation, and Council for Tobacco Research. A. M. Schmidt was supported by a fellowship from the Juvenile Diabetes Foundation. D. Stern completed this work during the tenure of a Genentech-Established Investigator Award from the American Heart Association.

\section{References}

1. Brownlee, M., A. Cerami, and H. Vlassara. 1988. Advanced glycosylation endproducts in tissue and the biochemical basis of diabetic complications. $N$. Engl. J. Med. 318:1315-1320.

2. Dyer, D., J. Blackledge, S. Thorpe, and J. Baynes. 1991. Formation of pentosidine during nonenzymatic browning of proteins by glucose. J. Biol. Chem. 266:11654-11660.

3. Sell, D., and V. Monnier. 1989. Structure elucidation of a senescence crosslink from human extracellular matrix. J. Biol. Chem. 264:21597-21602.

4. Cozzolino, F., M. Torcia, M. Ziche, S. Ogawa, J. Brett, S. Koga, H. Vlassara, P. Nawroth, and D. Stern. 1990. Advanced glycosylation endproducts stimulate endothelial cell growth in vitro and in vivo. Circulation. 82(Suppl.):142.

5. Esposito, C., H. Gerlach, J. Brett, D. Stern, and H. Vlassara. 1989. Endothelial receptor-mediated binding of glucose-modified albumin is associated with increased monolayer permeability and modulation of cell surface coagulant properties. J. Exp. Med. 170:1387-1407.

6. Kirstein, M., J. Brett, S. Radoff, S. Ogawa, D. Stern, and H. Vlassara. 1990. Advanced protein glycosylation induces transendothelial human monocyte chemotaxis and secretion of platelet-derived growth factor: role in vascular disease of diabetes and aging. Proc. Natl. Acad. Sci. USA. 87:9010-9014.

7. Vlassara, H., M. Brownlee, K. Manogue, C. Dinarello, and A. Pasagian. 1988. Cachectin/TNF and IL-1 induced by glucose-modified proteins: role in normal tissue remodeling. Science (Wash. DC). 240:1546-1548.

8. Neeper, M., A.-M. Schmidt, J. Brett, S.-D. Yan, F. Wang, Y.-C. Pan, K. Elliston, D. Stern, and A. Shaw. 1992. Cloning and expression of RAGE: a cell surface receptor for advanced glycosylation endproducts of proteins. J. Biol. Chem. 267:14998-15004.

9. Radoff, S., H. Vlassara, and A. Cerami. 1988. Characterization of a solubilized cell surface binding protein on macrophages specific for proteins modified nonenzymatically by advanced glycosylated end products. Arch. Biochem. Biophys. 263:418-423.

10. Schmidt, A.-M., M. Vianna, M. Gerlach, J. Brett, J. Ryan, J. Kao, C. Esposito, H. Hegarty, W. Hurley, M. Clauss, et al. 1992. Isolation and characterization of binding proteins for advanced glycosylation endproducts from lung tissue which are present on the endothelial cell surface. J. Biol. Chem. 267:14987-14997.

11. Yang, Z., J. Makita, Y. Horii, S. Brunelle, A. Cerami, P. Sehajpal, M. Suthanthiran, and H. Vlassara. 1991. Two novel rat liver membrane proteins that bind advanced glycosylation endproducts: relationship to macrophage receptor for glucose-modified proteins. J. Exp. Med. 174:515-524.

12. Vlassara, H., Z. Makita, E. Rayfield, E. Friedman, A. Cerami, and S. Morgello. 1990. In vivo advanced protein glycation as a signal for monocyte migration in the vessel wall: role in diabetes and aging. Circulation. 82(Suppl.):0362.

13. Quinn, M., S. Parthasarathy, L. Fong, and D. Steinberg. 1987. Oxidatively modified low density lipoproteins: a potential role in recruitment and retention of monocyte/macrophages during atherogenesis. Proc. Natl. Acad. Sci. USA. 84:2995-2998.
14. Lederman, S., M. Yellin, A. Cleary, R. Gulick, and L. Chess. 1990. Recombinant, truncated CD4 molecule (rT4) binds IgG. J. Immunol. 144:214-220.

15. Mosicki, R., E. Amento, S. Krane, J. Kurnick, and R. Colvin. 1983. Modulation of surface antigens of a human monocyte cell U937, during incubation with $\mathrm{T}$ lymphocyte conditioned medium: detection of $\mathrm{T} 4$ antigen and its presence on normal blood monocytes. J. Immunol. 131:743-748.

16. Laemmli, U. 1970. Cleavage of structural proteins during the assembly of the head of bacteriophage T4. Nature (Lond.). 227:680-685.

17. Johnson, D., J. Gautsch, J. Sportsman, and J. Elder. 1984. Improved technique utilizing non-fat dry milk for analysis of proteins and nucleic acids transferred to nitrocellulose. Gene Anal. Tech. 1:3-8.

18. Klotz, I., and D. Hunston. 1984. Mathematical models for ligand-receptor binding. J. Biol. Chem. 258:11442-11445.

19. Nawroth, P., D. McCarthy, W., Kisiel, D. Handley, and D. Stern. 1985. Cellular processing of bovine factor $\mathrm{X}$ and $\mathrm{Xa}$ by cultured bovine aortic endothelial cells. J. Exp. Med. 162:559-572.

20. Esposito, C., H. Gerlach, J. Brett, D. Stern, and H. Vlassara. 1989. Endothelial receptor-mediated binding of glucose-modified albumin is associated with increased monolayer permeability and modulation of cell surface coagulant properties. J. Exp. Med. 170:1387-1407.

21. Frens, G. 1973. Controlled nucleation for the regulation of particle size in monodisperse gold suspensions. Nature (Lond.). 241:22-24.

22. Ackerman, G., J. Yang, and K. Wolken. 1983. Differential surface labelling and internalization of glucagon by peripheral leukocyte. J. Histochem. Cytochem. 31:433-440.

23. Horrisberger, M., and M. VanLanthen. 1980. Ultrastructural localization of soybean agglutinin on thin sections of glycine matrix Var. Altona by the gold method. Histochemistry. 65:181-186.

24. Handley, D., and L. Witte. 1984. Platelet-derived growth factor labelled with colloidal gold for use as a mitogenic receptor probe. Eur. J. Cell Biol. 34:281-286.

25. Aznavoorian, S., M. Stracke, H. Krutzsch, E. Schiffmann, and L. Liotta. 1990. Signal transduction for chemotaxis and haptotaxis by matrix molecules in tumor cells. J. Cell Biol. 110:1427-1438.

26. Albrecht-Buehler, G. 1977. The phagokinetic tracks of 3T3 cells. Cell. 11:395-404.

27. Hutchens, T., J. Henry, and T.-T. Yip. 1991. Structurally intact forms of maternal lactoferrin purified from urine of preterm infants fed human milk: identification of a trypsin-like proteolytic cleavage event in vivo that does not result in fragment dissociation. Proc. Natl. Acad Sci. USA. 88:2994-2998.

28. Rochard, E., D. Legrand, J. Mazurier, J. Montreuil, and G. Spik. 1989. The N-terminal domain I of human lactotransferrin binds specifically to phytohemagglutinin-stimulated peripheral blood human lymphocyte receptors. FEBS (Fed. Eur. Biochem. Soc.) Lett. 255:201-204.

29. Vlassara, H., M. Brownlee, and A. Cerami. 1985. High affinity receptormediated uptake and degradation of glucose-modified proteins: a potential mechanism for the removal of senescent macromolecules. Proc. Natl. Acad. Sci. USA. 82:5588-5592.

30. Ross, R. 1986. The pathogenesis of atherosclerosis-an update. N. Engl.J. Med. 314:488-500.

31. Makita, Z., S. Radoff, E. Rayfield, Z. Yang, E. Skolnik, V. Delaney, E. Friedman, A. Cerami, and H. Vlassara. 1991. Advanced glycosylation endproducts in patients with diabetic nephropathy. $N$. Engl. J. Med. 325:836-842.

32. Schmidt, A.-M., R. Mora, J. Brett, J. Ryan, K. Kuwabara, and D. Stern. 1992. Soluble receptor for advanced glycosylation endproducts inhibits the interaction of AGE-albumin with receptors. Clin. Res. 40:193A.

33. Greenhalgh, D., K. Sprugel, M. Murray, and R. Ross. 1990. PDGF and FGF stimulate wound healing in the genetically diabetic mouse. Am. J. Pathol. 136:1235-1246.

34. Mora, R., A.-M. Schmidt, J. Brett, S.-D. Yan, and D. Stern. 1992. An unique $35 \mathrm{kDa}$ membrane protein and a soluble lactoferrin-like protein form a complex which constitutes the endothelial cell receptor for advanced glycosylation endproducts. FASEB (Fed. Am. Soc. Exp. Biol.) J. 6:A1593 (\#3801). 